\title{
Copper-exchanged $\mathrm{Y}$ zeolites for gasoline
} deep-desulfurization

Myriam L. M. Navarro Cerutti ${ }^{a, *}$, Fabiola V. Hackbarth ${ }^{b}$, Danielle Maass ${ }^{c}$, Sandra S. X. Chiaro $^{d}$, Ricardo R. C. Pinto ${ }^{e}$, Mauri J. B. Cardoso ${ }^{\text {, Pedro A. Arroyo }}{ }^{f}$, Antonio A. Ulson de Souza ${ }^{b}$, Selene M. A Guelli U. de Souza ${ }^{b, *}$

${ }^{\text {a}}$ Department of Chemical Engineering, Federal University of Paraná (UFPR), PO Box 19011, Zip-code 81531-980, Curitiba, PR - Brazil

bLaboratory of Mass Transfer, Federal University of Santa Catarina, PO Box 476, Zipcode 88040-900 Florianópolis, SC, Brazil

'Institute of Science and Technology, Federal University of São Paulo, Zip-code 12231280, São José dos Campos, SP, Brazil

${ }^{\mathrm{d}}$ Petrobras, Research and Development Center Leopoldo A. Miguez de Mello (CENPES), CEP: 21941-915, Rio de Janeiro - RJ. Brazil

ePetrobras, Marketing and Product Development, CEP: 20231-030, Rio de Janeiro - RJ. Brazil

${ }^{\mathrm{f}}$ Chemical Engineering Department, State University of Maringá. Maringá - PR. Brazil

*Corresponding authors: Tel.: (+55) (48) 37216444; Tel.: (+55) (41) 33613562

E-mail adresses: selene.souza@ufsc.br (Selene M. A. Guelli U. de Souza); loremnc@ufpr.br (Myriam L. M. Navarro Cerutti). 


\begin{abstract}
1 Abstract
3 Adsorptive desulfurization is one of the most efficient methods to remove recalcitrant

4 sulfur compounds from transportation fuels. Two $\pi$-complexation-based sorbents were

5 studied for desulfurization of synthetic gasoline. The sorbents were obtained by ion

6 exchanging $\mathrm{Y}$ zeolites with copper cations using different techniques, which includes

7 liquid phase ion exchange (CuY1) and vapor phase ion exchange (CuY2). Preliminary

8 kinetic and equilibrium experiments for sulfur adsorption in batch system showed that

$9 \mathrm{CuY} 1$ has the greatest desulfurization capacity and selectivity. The best adsorbent, CuY1

10 pellet, had a dynamic adsorption and equilibrium capacity of 2.97 and $4.14 \mathrm{mg} \mathrm{S} / \mathrm{g}$ for

11 fixed bed column assays, respectively. Experimental data obtained to batch reactor and

12 packed bed column have been interpreted by means of a pore diffusion model in which

13 the mass balance to the pellets are emphasized. The model proposed was able to fit well

14 to the experimental data. After the first thermal regeneration, the copper ion-exchanged

15 zeolite presented a maximum recovery of 91.5\%. The copper-exchanged zeolite (in pellet

16 form) has shown good uptake rate and regenerability for desulfurization of synthetic

17 gasoline.

19 Keywords: desulfurization; fixed-bed column; sulfur; synthetic gasoline; zeolite. 


\section{INTRODUCTION}

The sulfur content found in crude oil can vary between 0.05 and $6.00 \mathrm{wt} \%$, depending on the type and source of petroleum. The presence of sulfur compounds is undesirable in refineries since it can cause catalysts deactivation and several corrosion problems in pipelines, pumps, and refining equipment. Furthermore, the combustion of fossil fuels is responsible for great amounts of SOx emission. Sulfur oxides in the atmosphere can cause acid rain and important human health problems (Al-Bogami and de Lasa 2013). In order to reduce the SOx emissions, regulatory bodies worldwide are demanding ultra-low levels of sulfur content (<15 ppm) (Fallah et al. 2014). Thus, one of the main goals of petroleum refineries is to achieve the required deep-desulfurization levels (Song et al. 2016b).

Adsorptive desulfurization (ADS) (Tawfik et al. 2016), extractive desulfurization (Abro et al. 2014), biodesulfurization (BDS) (Maass et al. 2015), hydrodesulfurization (HDS), oxidative desulfurization (ODS) and precipitative desulfurization are some of the main techniques applied in the reduction of sulfur content from fossil fuels. HDS is the method most widely used due to its high efficiency in the removal of most aliphatic sulfur compounds such as mercaptans, sulphides, and disulfides from fuels (Dehghan and Anbia 2017). However, it is not effective in the removal of recalcitrant sulfur compounds such as thiophene (T), benzothiophene (BT), dibenzothiophene (DBT) and 4,6dimethyldibenzothiophene (DMDBT) (Maass et al. 2014). HDS also requires a considerable amount of energy since operates at high temperature and pressure (Nanoti et al. 2011).

Adsorptive desulfurization (ADS) has emerged as a promising alternative to HDS owing to its several advantages such as hydrogen-free operation, mild operating conditions and high selectivity (Moreira et al. 2017). Recent studies about ADS have focused on the development of a novel and adequate adsorbent that presents high adsorptive capacity, high selectivity and ease of regenerate. A wide variety of adsorbents has been used into ADS, such as activated carbons (Selvavathi et al. 2009; Seredych et al. 2009), mesoporous materials (Walcarius and Mercier 2010; Wu et al. 2012), metal ion-exchanged zeolites (Gong et al. 2009), metal-organic frameworks (MOFs) (Lammert et al. 2013; El Osta et al. 2012), silica gels and alumina (Moreira et al. 2017).

Shape selectivity can play a major role in determining the ADS capacity. The Y zeolites, in particular, have attracted a great deal of attention due to their unique faujasite pore 
1 structure, large surface area, and available surface acidity. Zeolite shape selectivity is the

2 result of the three-dimensional channels and cages. Moreover, the low Si/Al ratio of the

3 Y zeolite results in high Brønsted acid sites, which also present a significant role in sulfur

4 adsorption. Usually, $\mathrm{Y}$ zeolite is easily regenerated, being possible to be used in

5 consecutive adsorption/desorption cycles without loss of efficiency. These properties of

6 Y zeolite make this material one of the most remarkable in adsorptive desulfurization (Al-

$7 \quad$ Bogami and de Lasa 2013; Lee and Valla 2017).

8 Zeolites can be loaded with different metal ions $\left(\mathrm{Ag}^{+}, \mathrm{Cu}^{+}, \mathrm{Fe}^{2+}, \mathrm{K}^{+}, \mathrm{Ni}^{2+}\right.$, and $\mathrm{Zn}^{2+}$ or

$\left.9 \mathrm{Pd}^{2+}\right)$ through ion-exchange techniques. Ion-exchange improves the capacity of desulfurization due to the $\pi$-complexation (chemical complexation) formed between metal ions and sulfur compounds. $\pi$-Complexation occurs when metal ions form $\sigma$-bonds with free s-orbitals and the d-orbitals will back-donate electron density to the antibonding $\pi$-orbitals in the sulfur-containing ring of thiophenes (Dehghan and Anbia 2017; Yu et al. 2015).

Several works reported the zeolite $\mathrm{Y}$ containing copper cations as an effective adsorbent for removal of thiophenic sulfur molecules from gasoline and other heavier transportation fuels at ambient temperature (Hernández-Maldonado et al. 2005; King and Faz 2006; Li et al. 2006; Yang et al. 2001). This paper reports an investigation of thiophene removal from synthetic gasoline (with and without olefin) using copper exchange Y zeolite at ambient temperature. The effects of ion exchange technique and adsorbent configuration on the adsorption performance were examined. Fixed-bed column experiments using zeolite pellets were accomplished to determine desulfurization capacity in a continuous process. Finally, the regenerative capacity of the adsorbent was analyzed using different thermal regeneration techniques. 


\section{EXPERIMENTAL METHODS}

\subsection{Chemicals}

Sulfur species in gasoline comprise thiophene and alkyl-substituted thiophenes (King and Faz 2006). Thiophene (Sigma-Aldrich, $\geq 99.0 \%$ ) was selected as a sulfur compound model for desulfurization assays. The synthetic gasoline used in this study is a solvent mixture which consists in 50\% (v/v) n-octane (Sigma-Aldrich, 98.0\%) representing the paraffins; $10 \%$ (v/v) cyclohexane (Sigma-Aldrich, 99.5\%) as the naphthenes; $20 \%$ (v/v) cyclohexene (Sigma-Aldrich, $\geq 99.7 \%$ ) as the olefins; and 20\% (v/v) toluene (SigmaAldrich, 99.8\%), as aromatic hydrocarbons. The salts used in the ion exchange assays were $\mathrm{Cu}\left(\mathrm{NO}_{3}\right)_{2} .3 \mathrm{H}_{2} \mathrm{O}($ Merck, $\geq 99.5 \%$ ) and $\mathrm{CuCl}$ (Merck, $\geq 97.0 \%$ ).

\subsection{Zeolite Preparation}

The zeolite $\mathrm{NaY}$, used in the ion exchange, was kindly provided by the PETROBRAS' Research and Development Center (CENPES/PETROBRAS), Brazil. Based on the aluminum content, the theoretical cation exchange capacity (CEC) of this sample is $390 \mathrm{meq} / 100 \mathrm{~g}$, and the unit cell molar composition on a dry basis is $\mathrm{Na}^{+}{ }_{50}\left[\left(\mathrm{AlO}_{2}{ }^{-}\right.\right.$ )$\left._{50 .}\left(\mathrm{SiO}_{2}\right)_{142}\right]$.

The zeolite powder adsorbents were prepared and characterized as described in a previous work (Navarro et al. 2004). Two different methods were used in the preparation of CuY1 and CuY2 zeolites. Briefly, CuY1 was carried out by exchange with aqueous $\mathrm{Cu}\left(\mathrm{NO}_{3}\right)_{2} \cdot 3 \mathrm{H}_{2} \mathrm{O}$ solution followed by auto-reduction (Takahashi et al. 2001), and CuY2 was carried out by direct reaction between $\mathrm{NaY}$ zeolite with aqueous $\mathrm{CuCl}$ solution. After ion exchange, $\mathrm{CuY} 1$ samples were calcinated with a thermal profiling of $50^{\circ} \mathrm{C}(30 \mathrm{~min})$, $105^{\circ} \mathrm{C}(120 \mathrm{~min}), 200^{\circ} \mathrm{C}(120 \mathrm{~min}), 300^{\circ} \mathrm{C}(120 \mathrm{~min})$ and $450{ }^{\circ} \mathrm{C}(6 \mathrm{~h})$. The reduction of $\mathrm{Cu}^{2+}$ to $\mathrm{Cu}^{+}$can be performed in an environment containing: (i) a mixture of a reducing gas and an inert gas or (ii) only inert gas, when self-reduction occurs (Takahashi et al. 2001). Several works have reported the reduction of $\mathrm{Cu}^{2+}$ to $\mathrm{Cu}^{+}$in the zeolite in different conditions (Dedecek and Wichterlova 1994; Lee and Valla 2017; Wang et al. 2012). In this study, reduction of $\mathrm{Cu}^{2+}$ to $\mathrm{Cu}^{+}$was carried out either in, using an gaseous mixture of $5 \% \mathrm{~N}_{2}$ and $95 \% \mathrm{He}$ at a flow rate of $50 \mathrm{~mL} / \mathrm{min}$, the composition was arbitrarily chosen. $\mathrm{CuY} 2$ was not subjected to calcination. 
1 The CuY1 zeolite was shaped into pellet form. The pelletizing process was accomplished

2 in two steps with a formulation of $89.3 \mathrm{~g}$ and $104.4 \mathrm{~g}$ of CuY1 zeolite, $17 \mathrm{~g}$ and $16.89 \mathrm{~g}$

3 of pseudoboehmite, $72.7 \mathrm{~mL}$ and $103 \mathrm{~mL}$ of acetic acid (4\%), for the first and second stages, respectively (Handle 2007). Posteriorly, the molding of cylindrical pellets was carried out by extrusion using equipment with a $2 \mathrm{~mm}$ die. After molding, the pellets were dried at $120^{\circ} \mathrm{C}$ for $12 \mathrm{~h}$. Pellets were characterized according to the methods described on Table S3. Briefly, the porosity of pellets, average particle diameter, particle mass, apparent density and real density were measured.

\subsection{Preliminary Adsorption Assays}

The adsorbent with the best desulfurization capacity was determined through preliminary adsorption tests. The zeolites CuY1 and CuY2 were separated granulometrically for particle sizes between 150 and 270 mesh and then dried overnight at $120^{\circ} \mathrm{C}$. Adsorption kinetics were performed by adding $0.5 \mathrm{~g}$ of the adsorbent and $1000 \mathrm{mg} / \mathrm{L}$ of thiophene (381 mg/L of sulfur) into $5 \mathrm{~mL}$ of olefin-free synthetic gasoline containing $70 \%(\mathrm{v} / \mathrm{v})$ of n-octane; $10 \%(\mathrm{v} / \mathrm{v})$ cyclohexane and 20\% (v/v) toluene. The flasks remained in an orbital shaker at $900 \mathrm{rpm}, 25^{\circ} \mathrm{C}$, and aliquots were removed at time intervals of $1,3,5,10,15$, 20, 25, 30 and 60 min.

Equilibrium sorption studies occurred under constant orbital agitation (900 rpm) and temperature $\left(25^{\circ} \mathrm{C}\right)$. The experiments were performed in duplicate using initial sulfur concentrations ranging from $50-1100 \mathrm{mg} / \mathrm{L}$. The adsorbent $(0.5 \mathrm{~g})$ was added to $5 \mathrm{~mL}$ of olefin-free synthetic gasoline. After reaching the equilibrium (20 h), samples were collected, filtered (Fluoropore membrane FG, $0.22 \mu \mathrm{m}$ pore, Millipore) and then analyzed for residual sulfur concentration.

\subsection{Desulfurization of Synthetic Gasoline}

The kinetic desulfurization study was carried out by adding $15 \mathrm{~g}$ of dried adsorbent to $250 \mathrm{~mL}$ of synthetic gasoline containing $1000 \mathrm{mg} / \mathrm{L}$ of thiophene $(381 \mathrm{mg} / \mathrm{L}$ of sulfur). The flasks remained at room temperature under constant magnetic stirring. Aliquots were sampled at 1, 5, 10, 20, 40, 60, 90, 120, 180, 240, 300 and $360 \mathrm{~min}$. The experiments were performed in duplicate using pelletized and powdered $\mathrm{CuY} 1$ adsorbent. 
1 The equilibrium experiments consisted of adding $5 \mathrm{~g}$ of pelleted $\mathrm{CuY} 1$ to $50 \mathrm{~mL}$ of

2 synthetic gasoline containing different concentrations of sulfur (range $50-1100 \mathrm{mg} / \mathrm{L}$ ).

3 The flasks were kept at $25{ }^{\circ} \mathrm{C}$ under orbital shaking for $30 \mathrm{~h}$.

5

6 Column experiments were accomplished in a borosilicate glass column with $1.1 \mathrm{~cm}$ inner

\subsection{Column Experiments}

diameter and $45 \mathrm{~cm}$ length. The column was packed with $\mathrm{CuY} 1$ pellets $(\sim 40 \mathrm{~g})$ dried in an oven at $160^{\circ} \mathrm{C}$ for $5 \mathrm{~h}$ and, at this temperature, was quickly transferred to the column. Immediately after packing the column, nitrogen gas was fed up-flow through the column for $30 \mathrm{~min}$, to ensure that the adsorbent reached room temperature without absorbing moisture. After filling with the adsorbent, the synthetic gasoline enriched with thiophene was pumped up-flow through the column. Up-flow was adopted to ensure a better filling and distribution of the liquid in the column and thus avoid preferred paths. The experiment was start-up when the synthetic gasoline encountered the column bed. Table 1 presents the operation parameters used in the column experiments.

\section{Insert Table 1}

Samples from the column outlet were regularly collected and analyzed by gas chromatography. All experiments were carried out at room temperature $\left(\sim 25^{\circ} \mathrm{C}\right)$. After sorbent exhaustion, the loaded zeolite was regenerated using three different heat treatments as presented in Table 2 .

\section{Insert Table 2}

\subsection{Gas Chromatography Analysis}

All the thiophene samples were analyzed by gas chromatography (GC) using a Shimadzu GC-17A equipped with a flame ionization detector (FID). The GC was fitted with a 30.0 m capillary column (DB-5, J \& W Scientific) coated with a $0.25 \mu \mathrm{m}$ thick film of $5 \%$ 
1 phenyl methylpolysiloxane. Helium was employed as a carrier gas at a constant flow rate

2 of $15.42 \mathrm{~cm}^{3} / \mathrm{s}$ with a relative pressure of $50 \mathrm{kPa}$. The initial oven temperature of $35^{\circ} \mathrm{C}$

3 was held for $8.0 \mathrm{~min}$ and then programmed from 35 to $120^{\circ} \mathrm{C}$ at $70{ }^{\circ} \mathrm{C} / \mathrm{min}$ with an

4 isotherm held for $30 \mathrm{~min}$. A split injection (ratio 1:100) was carried out at $200{ }^{\circ} \mathrm{C}$

5 (Bandyopadhyay et al. 2013).

6

\section{THEORETICAL APPROACH}

8

\subsection{Modeling of Kinetics of Batch Adsorption}

According to Santacesaria et al. (1982a), internal diffusion in macropores can be considered the determining step due to geometric differences between the size of the microcrystals and the pellet. Thus, the model used to describe the adsorption phenomenon in batch reactor assumed the diffusion of adsorbate in the adsorbent macropores as the process controlling stage, and that the adsorption equilibrium is reached as soon as the adsorbate molecules complete their course in the macropore.

The mass transfer model was based on the following assumptions: (i) spherical particles of uniform diameter, (ii) isothermal process, and (iii) diffusion only in radial direction of the particle.

Mass conservation in the batch reactor:

$$
\begin{aligned}
& \frac{d C_{e}}{d t}=-\left.\varepsilon_{p} \frac{3}{r_{p}} D_{e} \frac{\left(1-\varepsilon_{e}\right)}{\varepsilon_{e}} \frac{\partial C_{p}}{\partial_{r}}\right|_{r_{p}} \\
& \varepsilon_{e}=\frac{V_{t}}{V_{t}+V_{a p}}
\end{aligned}
$$

where $C_{e}$ is the sulfur concentrations in liquid phase external to the particle $(\mathrm{mg} / \mathrm{L}), t$ is time, $r$ is the dimensionless radial coordinate inside the particle, $C_{p}$ is the sulfur concentration in liquid phase inside the particle $(\mathrm{mg} / \mathrm{L}), D_{e}$ is the effective diffusion coefficient through the particle area $\left(\mathrm{cm}^{2} / \mathrm{s}\right), \varepsilon_{p}$ is the porosity of the particle (dimensionless), $\varepsilon_{e}$ is the batch capacity factor (dimensionless), $r_{p}$ is the radius of the 
1 adsorbent particles (cm), $V_{t}$ volume of liquid outside the bath and $V_{a p}$ apparent volume of

2 the solid.

3 Mass conservation within an adsorbent particle can be described as:

4

$$
\frac{\partial C_{p}}{\partial t}=\frac{1}{r^{2}} D_{e} \frac{\partial}{\partial r}\left(r_{p}^{2} \frac{\partial C_{p}}{\partial r}\right)-\rho_{s} \frac{\left(1-\varepsilon_{p}\right)}{\varepsilon_{p}} \frac{\partial q^{*}}{\partial t}
$$

5

6 where $q^{*}$ is the concentration of the adsorbate in the solid phase $\left(\mathrm{mgS} / \mathrm{g}_{\text {solid }}\right)$ and $\rho_{s}$ is the 7 density of the solid phase $(\mathrm{g} / \mathrm{L})$.

8 In the solid phase of the adsorbent, it is considered that the adsorption pseudo-reaction is 9 very rapid compared to the mass transfer through macropores, i.e., the adsorption equilibrium is instantaneous when the adsorbate reaches the active site. Therefore, the solid phase equation can be defined as:

12

$$
\frac{\partial q^{*}}{\partial t}=\frac{d f_{e q}\left(C_{p}\right)}{d C_{p}} \frac{\partial C_{p}}{\partial t}
$$

14 Equation (4) is the Langmuir-Freundlich isotherm used in this work.

$$
f_{e q}\left(C_{p}\right)=q_{e}=\frac{q_{s} K C_{p}^{m}}{1+K C_{p}^{m}}
$$

The function $f_{e q}\left(C_{p}\right)$ describes the equilibrium relation between the phases solid and liquid. Where $q_{s}(\mathrm{mgS} / \mathrm{g})$ is the maximum adsorption capacity of the isotherm, $m$ is an empirical parameter of the Langmuir-Freundlich equation, and $K(\mathrm{~L} / \mathrm{mg})$ reflects the 19 affinity of the adsorbent for sulfur.

Initial and boundary conditions:

$$
\begin{array}{lll}
t=0 ; & & C_{e}=C_{e}^{o} \\
t=0, & r \geq 0 & C_{p}(r, 0)=C_{p}^{o}(r) \\
t>0, & r=r_{P} & C_{p}\left(r_{P}, t\right)=C_{e}(t)
\end{array}
$$




$$
\begin{array}{lll}
t>0, & r=0 & \left.\frac{\partial C_{P}}{\partial r}\right|_{r=0}=0 \\
t=0, & r \geq 0 & q_{e}=q_{e}^{o}
\end{array}
$$

1

2

$18 \frac{\partial C}{\partial t}+\frac{\partial(v C)}{\partial z}-D_{t} \frac{\partial^{2} C}{\partial z^{2}}=-\frac{\left(1-\varepsilon_{b}\right)}{\varepsilon_{b}} a_{p} K_{L}\left(C-C_{p}\right)$

\subsection{Pore Diffusion Model to a Fixed-Bed Column} and internal diffusion resistances and axial diffusion.

Mass conservation in the fluid phase:

Several models have been used to predict the dynamic behavior of a fixed-bed adsorption column. Liapis and Rippin (1978) developed a general fixed-bed model considering the effects of diffusional resistance to external and intraparticular mass transfer, and axial diffusion in the fluid. Later, Morbidelli et al. (1982) and Santacesaria et al. (1982a) proposed a model that translates the profile of concentrations within the particle into a single representative mean concentration (clustered model) and still considers the external

The model was developed considering the following assumptions: (i) uniform spherical particles; (ii) transient regime; (iii) constant and uniform temperature; (iv) cylindrical coordinates; (v) one-dimensional flow; (vi) constant and uniform bed porosity; (vii) absence of radial concentration gradients; (viii) no heat generation.

where $C$ is the concentration of the adsorbate in the liquid phase external to the particle, $C_{p}$ is the concentration of the adsorbate in the liquid phase inside the particle, $\varepsilon_{\mathrm{b}}$ is the porosity of the bed (dimensionless), $K_{L}$ is the global mass transfer coefficient, which can be evaluated from the external and internal mass transfer coefficients, $k_{e}$ and $k_{i}$, respectively, as: 
1 Mass conservation in the internal fluid phase:

2

$3 \quad \frac{\partial C_{P}}{\partial t}+\rho_{S} \frac{\left(1-\varepsilon_{p}\right)}{\varepsilon_{p}} \frac{\partial q^{*}}{\partial t}=\frac{a_{p} K_{L}}{\varepsilon_{p}}\left(C-C_{P}\right)$

4

5 Conservation mass balance for the solid phase of an adsorbent particle within the control

6 volume can be represented by Equation (3).

7 Initial and boundary conditions for Equations (10), (12) and (3) can be written as:

$8 \quad t=0, \quad(0<z<L) \quad C=0$

$9 \quad t=0, \quad(0<z<L) \quad C_{p}=0$

$10 \quad z=0,\left.\quad(t>0) \quad v C\right|_{z=0}-\left.D_{l} \frac{\partial C}{\partial z}\right|_{z=0}=v C_{0}$

$11 \quad(13)$

$12 \quad z=L,\left.\quad(t>0) \quad \frac{\partial C}{\partial z}\right|_{z=L}=0$

\subsection{Transport Parameters}

15 The axial dispersion coefficient was estimated using correlation as a function of Peclet

16 number, $P e_{p}$, and the Reynolds number, $R e$, defined by (Butt 2000):

$17 \varepsilon_{b} P e_{p}=0.2+0.011 R e^{0.48}$

$18 \quad D_{l}=\frac{v d_{p}}{P e_{p}}$

$19 R e=\frac{\rho_{l} v d_{p}}{\mu_{m}}$

21 where, $d_{p}$ is the diameter of the adsorbent particle, $\rho_{l}$ is the density of the liquid and $\mu_{m}$ 22 is the viscosity of the liquid mixture. 
1 The coefficient $k_{e}$ was calculated by the Sherwood number (Sh) (Santacesaria et al. 2 1982b), as a function of the number of Schmidt (Sc) and a modified definition of the 3 Reynolds number $\left(R e_{m}\right)$ that considers the form factor $(\varphi)$.

4

$5 \quad S h=\frac{k_{e} d_{p}}{D_{A m}}$

$6 \quad S c=\frac{\mu_{m}}{\rho_{l} D_{A m}}$

$7 \quad R e_{m}=\frac{\rho_{l} v d_{p}}{\mu_{m} 6\left(1-\varepsilon_{b}\right) \varphi}$

8

9 The molecular diffusivity $\left(D_{A m}\right)$ was estimated by applying the empirical correlation 10 using the molar volume $\left(V_{b}\right)$ indicated for organic solvents (Lusis and Ratcliff 1968).

$12 \quad \frac{D_{A m} \mu_{m}}{T}=\frac{8.52 \times 10^{-8}}{V_{b_{m}}^{1 / 3}}\left[1.40\left(\frac{V_{b_{m}}}{V_{b_{A}}}\right)^{1 / 3}+\left(\frac{V_{b_{m}}}{V_{b_{A}}}\right)\right]$

14 where, the molar volume of the mixture $\left(V_{b_{m}}\right)$ was estimated by calculating the Le Bas 15 volume, the viscosity of the mixture $\left(\mu_{m}\right)$ by the method of Chevron mixtures index and $16 \mathrm{~T}$ is temperature.

17 The average value of the internal mass transfer coefficient to the particle was proposed by Glueckauf (1955) and applied in this work to determine the $\bar{k}_{l}$,

19

$20 \quad \bar{k}_{\iota}=\frac{10 D_{A m} / \tau}{d_{p}}$

22 where, $\tau$ is the tortuosity.

23 Effective diffusion coefficient $\left(D_{e}\right)$ is calculate using the follow equation: 


$$
D_{e}=\frac{D_{A m}}{\tau}
$$

1

\subsection{Adsorption Capacity of the Bed}

3 The adsorption equilibrium capacity of the bed $\left(q_{c}\right)$ was obtained by mass balance. For

4 this, the stoichiometric time $\left(t_{s t}\right)$ was determined first from the breakthrough curves 5 according to the following equation:

6

$7 \quad t_{s t}=\int_{0}^{\infty}\left(1-\frac{C}{C_{0}}\right) d t$

8

9 For the pore diffusion model, the adsorption capacity of the bed $\left(q_{c}(\mathrm{mg} / \mathrm{g})\right.$, in 10

11

12

13

where $Q$ is the volumetric flow rate and $V$ is the total column volume.

$Q C_{0} t_{s t}=V \varepsilon_{b} C_{0}+V\left(1-\varepsilon_{b}\right) \varepsilon_{p} C_{0}+V\left(1-\varepsilon_{b}\right)\left(1-\varepsilon_{p}\right) q_{c} \rho_{s}$

\section{RESULTS AND DISCUSSION}

\subsection{Preliminary Desulfurization of Olefin-Free Synthetic Gasoline by Zeolite} Powder

To investigate the desulfurization process, kinetic and equilibrium sorption experiments were carried out using two copper exchanged Y zeolites, called CuY1 and CuY2. The experimental uptake rate sulfur from the synthetic olefin-free gasoline was studied as presented in Figure 1. 
1 The amount of S removed per gram of the solid adsorbent was calculated using the mass

2 conservation balance to the batch system (Equation (23)):

3

$4 \quad q=\frac{V}{W}\left(C_{b_{0}}-C_{b}\right)$

5

6 where $q$ is the uptake capacity for $\mathrm{S}$ (mg S/g of the adsorbent), $V(\mathrm{~L})$ is the volume of

7 solution, $W(\mathrm{~g})$ is the dry weight of the sorbent added, $C_{b_{0}}(\mathrm{mg} / \mathrm{L})$ and $C_{b}(\mathrm{mg} / \mathrm{L})$ are

8 the initial and final S concentrations at the solution, respectively.

9 The sorption was quite rapid as can be seen in Figure 1. The maximum uptake capacity for $\mathrm{S}$ was reached after $15 \mathrm{~min}$ to the $\mathrm{CuY} 1$ and to $\mathrm{CuY} 2$ the equilibrium is achieved for times longer than 60 minutes. About $38 \%$ of sulfur was removed when CuY1 was used and $22 \%$ for experiments with $\mathrm{CuY} 2$.

The adsorption kinetics were investigated applying the pseudo-first order kinetic model and a pseudo-second order kinetic model (Vilar et al. 2006). The results of the kinetic analysis are graphically presented in the supplementary material (see Figure S1). Table 3 presents the extrapolation results and the correlation coefficients of the pseudo-first and pseudo-second order adsorption kinetic models. According to the F-Test, for a confidence level of $95 \%$, there is no significant difference between the two models. However, other researchers found out that pseudo-second order model is more appropriate to describe the uptake values obtained to ADS using activated carbon, zeolite, alumina and metal organic frameworks (MOFs) as adsorbents (Muzic et al. 2010; Saleh 2018; Srivastav and Srivastava 2009; Yang et al. 2018).

Insert Table 3

The performance of $\mathrm{CuY} 1$ proved to be superior to the $\mathrm{CuY} 2$ since the adsorption capacities achieved from pseudo-first and pseudo-second order model were $1.04 \pm 0.01$ $\mathrm{mg} / \mathrm{g} / 1.08 \pm 0.01 \mathrm{mg} / \mathrm{g}$ and $0.60 \pm 0.04 \mathrm{mg} / \mathrm{g} / 0.73 \pm 0.05 \mathrm{mg} / \mathrm{g}$, respectively. These values are superior to that obtained by Muzic et al. (2010), when the adsorption capacity to ADS performed with activated carbon was $0.2098 \mathrm{mg} / \mathrm{g}$ and with zeolite was 
$10.0873 \mathrm{mg} / \mathrm{g}$. Thus demonstrating, the efficiency of the CuY1 zeolite against adsorbents

2 as activated carbon. However, the uptake values calculated from pseudo-first and pseudo3 second order model were higher (3.75 -17.50 mg/g depending on the initial concentration)

4 for ADS using commercial grade activated alumina as adsorbent.

5 To evaluate the total sulfur adsorption capacity of the CuY1 and CuY2 powder, 6 equilibrium studies using an olefin-free synthetic gasoline were performed at different 7 sulfur concentrations. The adsorption isotherms for the sulfur pollutant, using the two 8 types of adsorbents, are presented in Figure 2.

\section{Insert Figure 2}

Langmuir-Freundlich equilibrium model (Equation (4)) was fitted to the equilibrium data. Figure 2 shows that the Langmuir-Freundlich model fits well to the experimental equilibrium data for sulfur compound/adsorbent system. The estimated LangmuirFreundlich parameters are summarized in Table 4.

\section{Insert Table 4}

The maximum adsorption capacity for sulfur determined by the model was $2.50 \mathrm{mg} \mathrm{S} / \mathrm{g}$ for $\mathrm{CuY} 2$, lower than $\mathrm{CuY} 1$, which was $3.74 \mathrm{mg} \mathrm{S} / \mathrm{g}$. These preliminary adsorption experiments indicated that both adsorbents have affinity for thiophene, with CuY1 presenting a higher adsorption capacity of sulfur in olefin-free synthetic gasoline. The characterization of zeolites adsorbents revealed that $\mathrm{CuY} 1$ has a larger surface area and volumes of micropores (see Table S1), uniform crystalline structure and a larger Si/Al ratio (see Table S2).

According to Dehghan and Anbia (2017), Si/Al ratio has a significant impact on the adsorption of sulfur compounds since an increase in $\mathrm{Si} / \mathrm{Al}$ ratio appears to improve the desulfurization capacity. As the Si/Al ratio of Y zeolites increases, the number of Lewis acid sites increases and the number of Brönsted sites decreases. The adsorption capacity is clearly improved as the content of Lewis acid sites increases. These properties of $\mathrm{Y}$ zeolite can be beneficial for increasing the adsorption capacity to some sulfur compounds 
such as thiophene. Nevertheless, it was not possible to observe this phenomenon to $\mathrm{CuY} 1$

2 and $\mathrm{CuY} 2$, since the values of $\mathrm{Si} / \mathrm{Al}$ ratio were very similar to the $\mathrm{Si} / \mathrm{Al}$ ratio of $\mathrm{NaY}$ zeolite (see Table S2).

4 High content of $\mathrm{Cl}^{-}$and $\mathrm{Cu}^{2+}$ ions was detected in the adsorbent $\mathrm{CuY} 2$ (see Table S2).

5 The presence of these species leads to a reduction on the surface area and consequently

6 in the adsorptive capacity. Nonetheless, the presence of copper in the reduced state, with

7 a valence of 1 or 0 , facilities $\pi$-complexation bonds with $S$ molecules, which favors the 8 adsorption process (Yi et al. 2014).

9 The adsorbent CuY1 was selected to be used in batch and fixed bed experiments due to its advantages, such as: the desulfurization capacity and fast adsorption kinetics.

\subsection{Effect of Adsorbent Configuration on Synthetic Gasoline Desulfurization}

Zeolites can play a main role in sulfur adsorption due to their high adsorption capacity. However, the use of zeolites, in powder form, present several problems such as low mechanical resistance and agglomerates increasing, which hinders the feed flow and increases the pressure drop in fixed-bed columns. The purpose of adsorbent pelletization is to obtain a more resistant solid and to diminish the agglomerates. The pellet used in this work was obtained from the powder adsorbent $\mathrm{CuY} 1$. The characteristics of the pelletized CuY1 are in the supplementary material (see Tables S1 and S2).

Great variety of olefins are present in gasoline (Hancsók et al. 2011). Therefore, the study of $\mathrm{ADS}$ in the presence of these compounds is of paramount importance. The desulfurization performance of the powder CuY1 and pelletized CuY1 were evaluated through batch adsorption experiments with synthetic gasoline solution at room temperature and atmospheric pressure.

Figure 3 shows the profiles obtained for synthetic gasoline desulfurization using the adsorbent $\mathrm{CuY} 1$ in the pellets and powder forms. In both cases, the equilibrium was achieved after $150 \mathrm{~min}$. The adsorption percentage for synthetic gasoline solution (47\%) was higher than to olefin-free synthetic gasoline (38\%). However, the time to reach the equilibrium was much lower for experiments using olefin-free gasoline, only $15 \mathrm{~min}$, than to that using synthetic gasoline (150 min). 
2 The presence of olefin is undesired for the ADS process since a competitive adsorption 3 may occur. As discussed by Gong et al. (2009) and King and Li (2006), the behavior 4 reported here may be related to a possible interaction between the olefin molecules and

5 other components, modifying the resultant polarity of the solution.

6 The estimated pseudo-first and pseudo-second model parameters are summarized in

7 Table 5, and the fits of the models are graphically presented in the supplementary material 8 (see Figure S2). According to the F-Test, to a confidence level of 95\%, pseudo-second 9 order model provided a better fit to the experimental data. This suggests that the adsorptive desulfurization of synthetic gasoline follows the pseudo-second order kinetic model. As previously discussed, other authors also determined that pseudo-second order model is the best one to describe the kinetic of sulfur adsorption using zeolites as adsorbent (Muzic et al. 2010).

The desulfurization of synthetic gasoline was slightly faster using CuY1 powder as compared to the pelletized CuY1 (Table 5). The small size of zeolite powder particles facilitated the initial desulfurization rate since mass transfer resistance was probably diminished.

\section{Insert Table 5}

To provide a quantitative description of the adsorption process dynamics, a pore diffusion model to a batch reactor (described in the session 3.1) was applied to the experimental data obtained for the pelletized CuY1. The input data and the parameters of the mathematical model are summarized in Table S4 (see supplementary data). Figure 4 shows the evolution of experimental and estimated sulfur concentration during the adsorption onto the pellet $\mathrm{CuY} 1$ zeolite with contact time.

\section{Insert Figure 4}

The pore diffusion model fitted well to the experimental data, resulting in a mean deviation of $5.6 \%$. The adsorption phenomenon was successfully described considering 
1 adsorption equilibrium between the porous phase and the adsorbent surface. The controlling step for desulfurization process appears to be the diffusion to macroporous phase inside the pellets.

Figure 5 shows the equilibrium isotherm for synthetic gasoline using the pelletized adsorbent $\mathrm{CuY} 1$.

\section{Insert Figure 5}

Langmuir-Freundlich model (Equation (24)) fits well with the experimental equilibrium data for sulfur compound/adsorbent system (Figure 5). The estimated LangmuirFreundlich parameters are summarized in Table 6.

\section{Insert Table 6}

The maximum adsorption capacity of CuY1 pellets was $4.33 \mathrm{mg} \mathrm{S} / \mathrm{g}$ that is equivalent to $11.4 \mathrm{mg}$ thiophene/g. It is evident that an increase in adsorption capacity has occurred when these results are compared with those obtained using CuY1 (3.74 mg S/g) and CuY2 (2.50 mg S/g) powder adsorbents in olefin-free synthetic gasoline. According to Table S1, there is a slight decrease in the surface area (9.3\%) and the pore diameter was doubled after the pelletizing process of CuY1 zeolite. It is also observed a significant reduction in the area and volume of micropores, which represents a contribution of $82.7 \%$ in the external surface area. The pelletizing process of the CuY1 adsorbent, which occurred with the addition of the alumina binder, did not significantly affect the surface area and the particle agglomerates appear to form shallow pores of larger diameter, subsequently decreasing the material microporosity. Figure S3 illustrates the difference between the pore size of powder and pellet adsorbents. This graph represents the pore size distribution according to the Barrett-Joyner-Halenda $(\mathrm{BJH})$ method (Barrett et al. 1951). As shown in Figure $\mathrm{S} 4$, the $\mathrm{N}_{2}$ adsorption-desorption isotherms of $\mathrm{CuY} 1$ pellets exhibited type-IV, this is typical of capillary condensation of mesoporous materials with microporous contributions (Gregg and Sing 1982). The isotherm of the pellet presents an almost vertical branch in the first region of the curve. This is an indication of ease 
adsorption in the micropores present in the adsorbent. After micropores saturation, there

2 is a significant region of adsorption in larger pores or mesopores reaching a maximum of $309 \mathrm{~cm}^{3} / \mathrm{g}$ before capillary condensation. The $\mathrm{N}_{2}$ adsorption-desorption isotherms for $\mathrm{CuY} 1$ and CuY2 powder can be found in a previous work (Navarro et al. 2004). Zhang et al. (2008) also performed adsorption experiments using a batch method for removal of aromatic sulfur compounds. The model systems (solutions of n-octane/sulfur compounds with or without a small fraction of benzene/toluene) have been studied using Ag-Y and CuZn-Y modified zeolites as adsorbents. Results of batch experiments showed the capacity for $\mathrm{Ag}-\mathrm{Y}$, and $\mathrm{CuZn}-\mathrm{Y}$ were in the range 13.1 - 23.8 and $6.7-23.3 \mathrm{mg} \mathrm{S} / \mathrm{g}$, respectively. Co-presence of benzene and toluene in the adsorption system caused a competitive adsorption on the adsorbent, lowering the adsorption efficiency of organosulfur compounds (dibenzothiophene and 4,6-dimethyldibenzothiophene).

ADS of transportation fuels using metal-exchanged Y zeolites was studied by Lee and Valla (2017). Adsorption isotherms were carried out using a batch method. According to the Langmuir model, maximum adsorption capacities of 5.80 and $16.23 \mathrm{mg} \mathrm{S} / \mathrm{g}$ at $20^{\circ} \mathrm{C}$ were obtained using copper-exchanged zeolites in solutions containing benzothiophene or dibenzothiophene dissolved in n-octane, respectively.

The adsorption capacity achieved in this work was lower, but it must be taken into account that the dissolution of the adsorbate was carried out with compounds of different nature and amounts. The solvent played an important role in the adsorption behavior, interfering in the adsorbate-adsorbent interaction. Moreover, the presence of olefins in model fuels can strongly affect the adsorption performance (Sun et al. 2015; Velu et al. 2005; Velu et al. 2003; Wang et al. 2009) since the selective desulfurization from a mixture of hydrocarbons can be very challenging (Lee and Valla 2017).

\subsection{Fixed-Bed Adsorption Study}

The desulfurization of synthetic gasoline by $\mathrm{CuY} 1$ pellets was assessed in a continuous configuration using a packed bed column. CuY1 was selected to fixed-bed adsorption studies due to all the characteristics that the zeolite in the form of pellets offers for a continuous flow system. The experimental conditions used in each run are shown in Table S5 (see supplementary data). 
1 Figure 6 shows breakthrough curves for each one of the four assays. The profiles are different to the four experimental conditions. Thiophene breakthrough occurred instantly after the feed solution was eluted. Thus, the concentration of sulfur in the effluent rapidly increased. This occurrence was observed in both flow rates and was more accentuated for experiments $\mathrm{A}$ and $\mathrm{C}$, at flow rates of the $3.6 \mathrm{~mL} / \mathrm{min}$.

\section{Insert Figure 6}

The breakthrough times were 14.5, 43.5, 13.8 and 37.0 min for the experiments A, B, C, and $\mathrm{D}$, respectively. These times corresponded when the sulfur concentration in the column achieved $10 \%$ of the feed concentration. The stoichiometric time of experiment A (27.97 min) was shorter than the time for experiment B $(59.80 \mathrm{~min})$, as well as in the experiment $C$ (48.42 $\mathrm{min}$ ) concerning to experiment $\mathrm{D}(97.60 \mathrm{~min})$. It was verified that, from $\mathrm{A}$ to $\mathrm{B}$ and $\mathrm{C}$ to $\mathrm{D}$, respectively, as the flow was diminished, a longer time to saturate the column was needed.

The adsorption dynamic capacities obtained for the saturation cycles were 2.97, 3.99, 1.13, and $1.44 \mathrm{mg} \mathrm{S} / \mathrm{g}$ until the breakthrough point, for the experiments $\mathrm{A}, \mathrm{B}, \mathrm{C}$, and $\mathrm{D}$, respectively. The concentration value used as breakpoint corresponds $10 \%$ of the feed concentration. Furthermore, the adsorption equilibrium capacities were 4.14, 4.11, 3.31, and $3.27 \mathrm{mg} \mathrm{S} / \mathrm{g}$ for the experiments A, B, C, and D, respectively; calculated from of the equilibrium parameter, the stoichiometric time. It is possible to observe that the uptake capacities of $\mathrm{C}$ and $\mathrm{D}$ experiments decreased in comparison to the adsorption equilibrium capacity of CuY1 pellets (3.43 $\mathrm{mg} \mathrm{S} / \mathrm{g}$ ) for an equilibrium concentration of $400 \mathrm{mg} \mathrm{S} / \mathrm{L}$, as illustrated in Figure 5. The diminishing in adsorption capacities were 3.5 and $4.7 \%$ for $\mathrm{C}$ and $\mathrm{D}$ experiments, respectively. As the mass transfer is controlled by diffusion, the use of batch system provides ideal mixing conditions and reduces the diffusional limitation of sulfur compounds.

The mass transfer zone length $\left(\mathrm{L}_{\mathrm{MTZ}}\right)$ were $37.6,21.4,57.1$ and $49.7 \mathrm{~cm}$ for the breakthrough curve using a bed length of $39,39.3,40$, and $40 \mathrm{~cm}$ for the experiments $\mathrm{A}$, B, C, and D, respectively. Generating a fraction of unused bed $\left(f_{\mathrm{LUB}}\right)$ of $48,27,71$ and $62 \%$, respectively. These results indicate that the exchange zone was not fully developed 
1 for experiments $\mathrm{C}$, and D, since the $\mathrm{L}_{\mathrm{MTZ}}$ was higher than the bed height; resulting in a

2 very high non-used bed fraction. For the experiments A, B, the mass transfer zone was 3 completely developed, since LMTZ was smaller than the bed length. However, the values 4 obtained for $\mathrm{f}_{\mathrm{LUB}}$ indicate a mass transfer resistance. According to the data presented 5 above, the adsorption dynamic capacity was depend on the flow rate. When the flow rate 6 was increased of 1.8 to 3.6, the mass transfer zone also increased, since the contact time 7 was not long enough to permit the molecules adsorption. Therefore, the dynamic capacity 8 decreased, suggesting that mass transfer is the limiting step and the macropores control the process. Moreover, the adsorption capacity increased concomitantly with the feed concentration.

Table 7 shows that the sulfur uptake capacity obtained in this work is competitive with others reported in the literature for different types of adsorbents and different experimental conditions in a fixed-bed sorption system. Several authors report that the acidity of zeolite influences the desulfurization process. And depending on the type of metal and the method used in the ion exchange, a change in the desulfurization performance will be noticed (Dehghan and Anbia 2017; Hernández-Maldonado et al. 2005; Lee and Valla 2017; Li et al. 2016). It has to be mentioned that in sulfur removal some chemical reactions may occur leading to the production of heavier sulfur compounds, most of them remain inside the zeolite while others can be eluted (King and Faz 2006; King and Li 2006).

\section{Insert Table 7}

During the adsorption runs, was observed a change of color in the bed. The adsorbent change coloring from light blue to gray, reaching almost black. Other authors studied this phenomenon in several zeolites. This is an evidence of interaction with hydrocarbonsulfur molecules (Hernández-Maldonado and Yang 2003; King and Li 2006; Song et al. 2013). According to Satokawa et al. (2002), the change in zeolite color is a very helpful adsorption characteristic because the life of adsorbent can be judged simply and reliably depending on its color change. 
1 An aggregate diffusion model described in section 3.2 was fitted to the experimental data

2 in order to predict the breakthrough curves. The input data applied to each situation in the

3 program and the model parameters are shown in Tables S5 and 8, respectively.

5

6 The model adequately predicts the experimental results as presented in Figure 7. The 7

\section{Insert Table 8} lowest mean deviations, 4.0 and $4.3 \%$, were obtained in experiments $\mathrm{A}$ and $\mathrm{C}$, respectively, and the highest, 18.2 and $10.9 \%$, in the experiments $\mathrm{B}$ and $\mathrm{D}$, respectively. Thus, the pore diffusion model can be used to predict breakthrough curves for desulfurization process of synthetic gasoline by $\mathrm{CuY} 1$ pellets in fixed-bed columns. There is an indication that the controlling step for ADS process is the adsorbent pores diffusion. Although, the feed rate was changed, which directly affects the external mass transfer coefficient, the overall mass transfer coefficient was not modified (Table 8).

\subsubsection{Regeneration}

The impact of regeneration on the adsorbent lifetime is an important issue from the economic and environmental standpoints, therefore assessing the viability of the adsorbent in this regard is paramount. There are two techniques for regeneration of the zeolites adsorbent, the thermal treatment and the solvent elution (Dehghan and Anbia 2017; Gong et al. 2009). In this study, the thermal treatment is adopted and the adsorbent used is regenerated by three methods, as described in section 2.5 (Table).

Using method 1, the adsorbent departed from black to dark brown and uniform color with the first step, (Figure S5a). Then, in the second step, the zeolite was subjected to $350{ }^{\circ} \mathrm{C}$ in the muffle furnace for $3 \mathrm{~h}$, and partial recovery of the original color was achieved (Figure S5b). The same occurred with method 2, (Figure S6). After the muffle treatment (Figure S6b), many pellets were in brown tones of lower intensity than that obtained with method 1, indicating that the rotary evaporator drying treatment of method 2 was more efficient in color recovery. Regarding method 3, the adsorbent original color was recovered (Figure S7b and Figure S7c) after the same submitted to the same treatment in a muffle at $350{ }^{\circ} \mathrm{C}$. 
1 Since the zeolite dark color could be related to the formation of sulfur compounds with

2 copper, the method 3 was selected to analyze the adsorption capacity resulting from new

3 adsorption runs under similar conditions to the initial assays. Therefore, the CuY1 pellets,

4 used in the experiments $\mathrm{A}$ and $\mathrm{B}$, were submitted to the heat treatment described in

5 method 3.

6 Figure 7 shows the breakthrough curves obtained with: (a) the regeneration run A and (b) 7 regeneration run $\mathrm{B}$.

8

\section{Insert Figure 7}

Adsorption equilibrium capacity achieved using the regenerated bed was $3.79 \mathrm{mg} \mathrm{S} / \mathrm{g}$ for regeneration $\mathrm{A}$ and $3.73 \mathrm{mg} \mathrm{S} / \mathrm{g}$ for regeneration $\mathrm{B}$. The second recovery cycle provided 91.5 and $90.7 \%$ of adsorption for the experiments A and B, respectively.

In thermal regeneration process, it can occur the formation of some side sulfur compounds, for example sulfides, disulfides and polysulfides. These newly formed sulfur compounds are strongly adsorbed onto the zeolites due to their higher molecular weight, occupying the active sites of the adsorbent and thus reducing its desulfurization capacity (Dehghan and Anbia 2017).

Similar results were found in the literature, demonstrating the good regeneration capacity of the zeolites when saturated with sulfur compounds. Zhang et al. (2008) demonstrated that a full regeneration of $\mathrm{Ag}-\mathrm{Y}$ can be achieved by air calcination at $450{ }^{\circ} \mathrm{C}$. Song et al. (2016a) evaluated the regeneration of the AgCeY zeolites and showed that after five cycles of regeneration-adsorption, the adsorbent regenerability was excellent. Among several experiments, a maximum decrease in the sulfur removal $(\sim 17.6 \%)$ was obtained. Tian et al. (2012) performed the regeneration of the adsorbent Ce-Beta zeolite ( $\mathrm{Si} / \mathrm{Al}$ $=40$ ) at $450^{\circ} \mathrm{C}$, under dried nitrogen flow for $2 \mathrm{~h}$, and then in a muffle for $4 \mathrm{~h}$. The cerium ion-exchanged adsorbent showed about $80 \%$ recovery of desulfurization after the first regeneration. Tian et al. (2014) studied the reusability of meso-CeY. The procedure of regeneration was carried out at $450{ }^{\circ} \mathrm{C}$, under dried nitrogen flow for $2 \mathrm{~h}$, and then in a muffle for $4 \mathrm{~h}$. The sulfur removal decreased 6.9 and $13.9 \%$ after the fourth regeneration, in a model gasoline, with the presence of toluene and cyclohexene, respectively. 
1 In this sense, an important criterion for adsorbent development is that whether it can be

2 regenerated for multiple uses. According to literature data, zeolites exchanged with metals has demonstrated their excellent capacity of regeneration.

\section{CONCLUSIONS}

6 Y zeolite containing copper ions (treated by LPIE technique - CuY1) has been shown to

7 be effective for the removal of thiophenic sulfur compounds from a complex mixture

8 called synthetic gasoline. Desulfurization effectiveness was found to increase with the

9 use of synthetic gasoline instead of olefin-free synthetic gasoline. The configuration of

$10 \mathrm{CuY} 1$ adsorbent, powder or pellets, interfered in the sulfur adsorption. Desulfurization performance was increased by the presence of mesoporous in the CuY1 pellets. The sulfur adsorption capacity for the fixed-bed column experiments using $\mathrm{CuY} 1$ pellets and synthetic gasoline was similar to the values obtained in batch assays. Thermal regeneration of zeolite $\mathrm{CuY} 1$ was found to be efficient, presenting a bed recovery about $90 \%$.

\section{ACKNOWLEDGEMENTS}

The authors acknowledge CENPES/PETROBRAS for supplying the NaY zeolite and for providing laboratory facilities. The authors are also grateful to LABMASSA - Mass Transfer Laboratory, for the available laboratorial infrastructure. Danielle Maass is thankful to São Paulo Research Foundation (FAPESP) for the research grant 2019/076594.

\section{REFERENCES}

Abro, R., Abdeltawab, A.A., Al-Deyab, S.S., Yu, G., Qazi, A.B., Gao, S., Chen, X.: A review of extractive desulfurization of fuel oils using ionic liquids. RSC Adv. 4, 3530235317 (2014). doi:10.1039/C4RA03478C

Al-Bogami, S.A., de Lasa, H.I.: Catalytic conversion of benzothiophene over a HZSM5 based catalyst. Fuel. 108, 490-501 (2013). doi:https://doi.org/10.1016/j.fuel.2012.11.008

Bandyopadhyay, S., Chowdhury, R., Bhattacharjee, C., Pan, S.: Simultaneous production of biosurfactant and ULSD (ultra low sulfur diesel) using Rhodococcus sp. in a chemostat. Fuel. 113, 107-112 (2013). doi:https://doi.org/10.1016/j.fuel.2013.05.036 
Barrett, E.P., Joyner, L.G., Halenda, P.P.: The Determination of Pore Volume and Area Distributions in Porous Substances. I. Computations from Nitrogen Isotherms. J. Am. Chem. Soc. 73, 373-380 (1951). doi:10.1021/ja01145a126

Butt, J.B.: Reaction kinetics and reactor design. CRC Press (2000)

Dastanian, M., Seyedeyn-Azad, F.: Desulfurization of Gasoline over Nanoporous Nickel-Loaded Y-Type Zeolite at Ambient Conditions. Ind. Eng. Chem. Res. 49, 11254-11259 (2010). doi:10.1021/ie100941s

Dehghan, R., Anbia, M.: Zeolites for adsorptive desulfurization from fuels: A review. Fuel Process. Technol. 167Dehghan, 99-116 (2017). doi:https://doi.org/10.1016/j.fuproc.2017.06.015

Fallah, R.N., Azizian, S., Reggers, G., Carleer, R., Schreurs, S., Ahenach, J., Meynen, V., Yperman, J.: Effect of aromatics on the adsorption of thiophenic sulfur compounds from model diesel fuel by activated carbon cloth. Fuel Process. Technol. 119, 278-285 (2014). doi:https://doi.org/10.1016/j.fuproc.2013.11.016

Glueckauf, E.: Theory of chromatography. Part 10.-Formulæ for diffusion into spheres and their application to chromatography. Trans. Faraday Soc. 51, 1540-1551 (1955)

Gong, Y., Dou, T., Kang, S., Li, Q., Hu, Y.: Deep desulfurization of gasoline using ionexchange zeolites: $\mathrm{Cu}(\mathrm{I})$ - and $\mathrm{Ag}(\mathrm{I})$-beta. Fuel Process. Technol. 90, 122-129 (2009). doi:http://dx.doi.org/10.1016/j.fuproc.2008.08.003

Hancsók, J., Marsi, G., Kasza, T., Kalló, D.: Hydrogenation of the Aromatics and Olefins in FCC Gasoline During Deep Desulphurisation. Top. Catal. 54, 1102 (2011). doi:10.1007/s11244-011-9731-9

Handle, F.: Extrusion in Ceramics (Engineering Materials and Processes). , Berlim (2007)

Hernández-Maldonado, A.J., Yang, F.H., Qi, G., Yang, R.T.: Desulfurization of transportation fuels by $\pi$-complexation sorbents: $\mathrm{Cu}(\mathrm{I})-, \mathrm{Ni}(\mathrm{II})-$, and $\mathrm{Zn}(\mathrm{II})$-zeolites. Appl. Catal. B Environ. 56, 111-126 (2005). doi:http://dx.doi.org/10.1016/j.apcatb.2004.06.023

Hernández-Maldonado, A.J., Yang, R.T.: Desulfurization of liquid fuels by adsorption via $\pi$ complexation with $\mathrm{Cu}(\mathrm{I})-\mathrm{Y}$ and $\mathrm{Ag}-\mathrm{Y}$ zeolites. Ind. Eng. Chem. Res. 42, $123-$ 129 (2003)

J. Dedecek, B.W.: Siting and redox behavior of Cu ions in CuH-ZSM-5 zeolites. Cu+ photoluminescence study. J. Phys. Chem. 98, 5721-5727 (1994)

King, D.L., Faz, C.: Desulfurization of Tier 2 gasoline by divalent copper-exchanged zeolite Y. Appl. Catal. A Gen. 311, 58-65 (2006).

doi:https://doi.org/10.1016/j.apcata.2006.06.002

King, D.L., Li, L.: Removal of sulfur components from low sulfur gasoline using copper exchanged zeolite Y at ambient temperature. Catal. Today. 116, 526-529 (2006). doi:http://dx.doi.org/10.1016/j.cattod.2006.06.026

Lammert, M., Bernt, S., Vermoortele, F., De Vos, D.E., Stock, N.: Single- and MixedLinker Cr-MIL-101 Derivatives: A High-Throughput Investigation. Inorg. Chem. 52, 
8521-8528 (2013). doi:10.1021/ic4005328

Lee, K.X., Valla, J.A.: Investigation of metal-exchanged mesoporous Y zeolites for the adsorptive desulfurization of liquid fuels. Appl. Catal. B Environ. 201, 359-369 (2017). doi:http://dx.doi.org/10.1016/j.apcatb.2016.08.018

Li, H., Han, X., Huang, H., Wang, Y., Zhao, L., Cao, L., Shen, B., Gao, J., Xu, C.: Competitive adsorption desulfurization performance over K - Doped NiY zeolite. J. Colloid Interface Sci. 483, 102-108 (2016). doi:http://dx.doi.org/10.1016/j.jcis.2016.08.024

Li, X., Zhang, X., Lei, L.: Preparation of CuNaY zeolites with microwave irradiation and their application for removing thiophene from model fuel. Sep. Purif. Technol. 64, 326-331 (2009). doi:https://doi.org/10.1016/j.seppur.2008.10.016

Li, Y., Yang, F.H., Qi, G., Yang, R.T.: Effects of oxygenates and moisture on adsorptive desulfurization of liquid fuels with $\mathrm{Cu}(\mathrm{I}) \mathrm{Y}$ zeolite. Catal. Today. 116, 512 518 (2006). doi:https://doi.org/10.1016/j.cattod.2006.06.037

Liapis, A.I., Rippin, D.W.T.: The simulation of binary adsorption in activated carbon columns using estimates of diffusional resistance within the carbon particles derived from batc. Chem. Eng. Sci. 33, 593-600 (1978). doi:http://dx.doi.org/10.1016/00092509(78)80021-9

Lifeng Wang, Baode Sun, Frances H.Yang, R.T.Y.: Effects of aromatics on desulfurization of liquid fuel by $\pi$-complexation and carbon adsorbents. Chem. Eng. Sci. 73, 208-217 (2012). doi:10.1016/J.CES.2012.01.056

Lin, L., Zhang, Y., Zhang, H., Lu, F.: Adsorption and solvent desorption behavior of ion-exchanged modified Y zeolites for sulfur removal and for fuel cell applications. J. Colloid Interface Sci. 360, 753-759 (2011). doi:http://dx.doi.org/10.1016/j.jcis.2011.04.075

Lusis, M.A., Ratcliff, C.A.: Diffusion in binary liquid mixtures at infinite dilution. Can. J. Chem. Eng. 46, 385-387 (1968)

Maass, D., de Oliveira, D., de Souza, A.A.U., Souza, S.M.A.G.U.: Biodesulfurization of a System Containing Synthetic Fuel Using Rhodococcus erythropolis ATCC 4277. Appl. Biochem. Biotechnol. 174, 2079-2085 (2014). doi:10.1007/s12010-014-1189-3

Maass, D., Todescato, D., Moritz, D.E., Oliveira, J.V., Oliveira, D., Ulson de Souza, A.A., Guelli Souza, S.M.A.: Desulfurization and denitrogenation of heavy gas oil by Rhodococcus erythropolis ATCC 4277. Bioprocess Biosyst. Eng. 38, 1447-1453 (2015). doi:10.1007/s00449-015-1386-7

Morbidelli, M., Servida, A., Storti, G., Carra, S.: Simulation of multicomponent adsorption beds. Model analysis and numerical solution. Ind. Eng. Chem. Fundam. 21, 123-131 (1982). doi:10.1021/i100006a005

Moreira, A.M., Brandão, H.L., Hackbarth, F. V, Maass, D., Ulson de Souza, A.A., Guelli U. de Souza, S.M.A.: Adsorptive desulfurization of heavy naphthenic oil: Equilibrium and kinetic studies. Chem. Eng. Sci. 172, 23-31 (2017). doi:https://doi.org/10.1016/j.ces.2017.06.010

Muzic, M., Sertic-Bionda, K., Gomzi, Z., Podolski, S., Telen, S.: Study of diesel fuel desulfurization by adsorption. Chem. Eng. Res. Des. 88, 487-495 (2010). 
doi:https://doi.org/10.1016/j.cherd.2009.08.016

Nair, S., Tatarchuk, B.J.: Characteristics of sulfur removal by silver-titania adsorbents at ambient conditions. Adsorption. 17, 663-673 (2011). doi:10.1007/s10450-011-93622

Nanoti, A., Dasgupta, S., Agnihotri, V., Gupta, P., Goswami, A.N., Garg, M.O., Tangstad, E., Stöcker, M., Karlsson, A., Vistad, Ø.B.: A zeolite based vapor phase adsorptive desulfurization process for naphtha. Microporous Mesoporous Mater. 146, 158-165 (2011). doi:https://doi.org/10.1016/j.micromeso.2011.01.009

Navarro, M.L.M., Chiaro, S.S.X., Pinto, R.R.C., Arroyo, P.A., Souza, A.A.U. de, Souza, S.M.A.G.U. de: Tecnología limpia para el aprovechamiento de olefinas ligeras. (2004)

El Osta, R., Carlin-Sinclair, A., Guillou, N., Walton, R.I., Vermoortele, F., Maes, M., de Vos, D., Millange, F.: Liquid-Phase Adsorption and Separation of Xylene Isomers by the Flexible Porous Metal-Organic Framework MIL-53(Fe). Chem. Mater. 24, 27812791 (2012). doi:10.1021/cm301242d

Saleh, T.A.: Simultaneous adsorptive desulfurization of diesel fuel over bimetallic nanoparticles loaded on activated carbon. J. Clean. Prod. 172, 2123-2132 (2018). doi:https://doi.org/10.1016/j.jclepro.2017.11.208

Santacesaria, E., Morbidelli, M., Danise, P., Mercenari, M., Carra, S.: Separation of xylenes on Y zeolites. 1. Determination of the adsorption equilibrium parameters, selectivities, and mass transfer coefficients through finite bath experiments. Ind. Eng. Chem. Process Des. Dev. 21, 440-445 (1982)(a). doi:10.1021/i200018a016

Santacesaria, E., Morbidelli, M., Servida, A., Storti, G., Carra, S.: Separation of xylenes on Y zeolites. 2. Breakthrough curves and their interpretation. Ind. Eng. Chem. Process Des. Dev. 21, 446-451 (1982)(b). doi:10.1021/i200018a017

Sarda, K.K., Bhandari, A., Pant, K.K., Jain, S.: Deep desulfurization of diesel fuel by selective adsorption over Ni/Al2O3 and Ni/ZSM-5 extrudates. Fuel. 93, 86-91 (2012). doi:http://dx.doi.org/10.1016/j.fuel.2011.10.020

Selvavathi, V., Chidambaram, V., Meenakshisundaram, A., Sairam, B., Sivasankar, B.: Adsorptive desulfurization of diesel on activated carbon and nickel supported systems. Catal. Today. 141, 99-102 (2009). doi:https://doi.org/10.1016/j.cattod.2008.05.009

Seredych, M., Lison, J., Jans, U., Bandosz, T.J.: Textural and chemical factors affecting adsorption capacity of activated carbon in highly efficient desulfurization of diesel fuel. Carbon N. Y. 47, 2491-2500 (2009). doi:https://doi.org/10.1016/j.carbon.2009.05.001

Song, H., Gao, H., Song, H., Yang, G., Li, X.: Effects of Si/Al Ratio on Adsorptive Removal of Thiophene and Benzothiophene over Ion-Exchanged AgCeY Zeolites. Ind. Eng. Chem. Res. 55, 3813-3822 (2016)(a). doi:10.1021/acs.iecr.5b04609

Song, H., Wan, X., Dai, M., Zhang, J., Li, F., Song, H.: Deep desulfurization of model gasoline by selective adsorption over $\mathrm{Cu}-\mathrm{Ce}$ bimetal ion-exchanged $\mathrm{Y}$ zeolite. Fuel Process. Technol. 116, 52-62 (2013). doi:http://dx.doi.org/10.1016/j.fuproc.2013.04.017

Song, H., Yang, G., Song, H., Cui, X., Li, F., Yuan, D.: Kinetic and thermodynamic studies on adsorption of thiophene and benzothiophene onto AgCeY Zeolite. J. Taiwan 
Inst. Chem. Eng. 63, 125-132 (2016)(b). doi:https://doi.org/10.1016/j.jtice.2016.02.020

Srivastav, A., Srivastava, V.C.: Adsorptive desulfurization by activated alumina. J. Hazard. Mater. 170, 1133-1140 (2009). doi:https://doi.org/10.1016/j.jhazmat.2009.05.088

Sun, H.-Y., Sun, L.-P., Li, F., Zhang, L.: Adsorption of benzothiophene from fuels on modified NaY zeolites. Fuel Process. Technol. 134, 284-289 (2015).

doi:http://dx.doi.org/10.1016/j.fuproc.2015.02.010

Takahashi, A., Yang, R.T., Munson, C.L., Chinn, D.: Cu(I)-Y-Zeolite as a Superior Adsorbent for Diene/Olefin Separation. Langmuir. 17, 8405-8413 (2001). doi:10.1021/la011196z

Tawfik, A.S., Gaddafi, I.D., Taye Damola, S.: Nanocomposites and Hybrid Materials for Adsorptive Desulfurization. In: Tawfik, A.S. (ed.) Applying Nanotechnology to the Desulfurization Process in Petroleum Engineering. pp. 129-153. IGI Global, Hershey, PA, USA (2016)

Teymouri, M., Samadi-Maybodi, A., Vahid, A., Miranbeigi, A.: Adsorptive desulfurization of low sulfur diesel fuel using palladium containing mesoporous silica synthesized via a novel in-situ approach. Fuel Process. Technol. 116, 257-264 (2013). doi:http://dx.doi.org/10.1016/j.fuproc.2013.07.009

Tian, F., Shen, Q., Fu, Z., Wu, Y., Jia, C.: Enhanced adsorption desulfurization performance over hierarchically structured zeolite Y. Fuel Process. Technol. 128, 176182 (2014). doi:https://doi.org/10.1016/j.fuproc.2014.07.018

Tian, F., Yang, X., Shi, Y., Jia, C., Chen, Y.: Adsorptive desulfurization over hierarchical beta zeolite by alkaline treatment. J. Nat. Gas Chem. 21, 647-652 (2012). doi:https://doi.org/10.1016/S1003-9953(11)60414-3

Velu, S., Ma, X., Song, C.: Selective Adsorption for Removing Sulfur from Jet Fuel over Zeolite-Based Adsorbents. Ind. Eng. Chem. Res. 42, 5293-5304 (2003). doi:10.1021/ie020995p

Velu, S., Song, C., Engelhard, M.H., Chin, Y.-H.: Adsorptive Removal of Organic Sulfur Compounds from Jet Fuel over K-Exchanged NiY Zeolites Prepared by Impregnation and Ion Exchange. Ind. Eng. Chem. Res. 44, 5740-5749 (2005). doi:10.1021/ie0488492

Vilar, V.J.P., Botelho, C.M.S., Boaventura, R.A.R.: Equilibrium and kinetic modelling of Cd(II) biosorption by algae Gelidium and agar extraction algal waste. Water Res. 40, 291-302 (2006). doi:https://doi.org/10.1016/j.watres.2005.11.008

Walcarius, A., Mercier, L.: Mesoporous organosilica adsorbents: nanoengineered materials for removal of organic and inorganic pollutants. J. Mater. Chem. 20, 44784511 (2010). doi:10.1039/B924316J

Wang, H., Song, L., Jiang, H., Xu, J., Jin, L., Zhang, X., Sun, Z.: Effects of olefin on adsorptive desulfurization of gasoline over Ce(IV)Y zeolites. Fuel Process. Technol. 90, 835-838 (2009). doi:http://dx.doi.org/10.1016/j.fuproc.2009.03.004

Wu, X.-W., Ma, H.-W., Zhang, L.-T., Wang, F.-J.: Adsorption properties and mechanism of mesoporous adsorbents prepared with fly ash for removal of $\mathrm{Cu}$ (II) in aqueous solution. Appl. Surf. Sci. 261, 902-907 (2012). 
doi:https://doi.org/10.1016/j.apsusc.2012.08.122

2 Yang, K., Yan, Y., Chen, W., Kang, H., Han, Y., Zhang, W., Fan, Y., Li, Z.: The High

3 Performance and Mechanism of Metal-organic Frameworks and Their Composites in

4 Adsorptive Desulfurization. Polyhedron. (2018).

5 doi:https://doi.org/10.1016/j.poly.2018.06.036

6 Yang, R.T., Takahashi, A., Yang, F.H.: New Sorbents for Desulfurization of Liquid

7 Fuels by $\pi$-Complexation. Ind. Eng. Chem. Res. 40, 6236-6239 (2001).

8 doi:10.1021/ie010729w

9 Yi, D., Huang, H., Meng, X., Shi, L.: Adsorption-desorption behavior and mechanism

10 of dimethyl disulfide in liquid hydrocarbon streams on modified Y zeolites. Appl. Catal.

11 B Environ. 148, 377-386 (2014). doi:http://dx.doi.org/10.1016/j.apcatb.2013.11.027

12 Yu, M., Zhang, N., Fan, L., Zhang, C., He, X., Zheng, M., Li, Z.: Removal of organic 13 sulfur compounds from diesel by adsorption on carbon materials,

14 https://www.degruyter.com/view/j/revce.2015.31.issue-1/revce-2014-0017/revce-2014-

15 0017.xml, (2015)

16 Zhang, Z.Y., Shi, T.B., Jia, C.Z., Ji, W.J., Chen, Y., He, M.Y.: Adsorptive removal of 17 aromatic organosulfur compounds over the modified Na-Y zeolites. Appl. Catal. B

18 Environ. 82, 1-10 (2008). doi:http://dx.doi.org/10.1016/j.apcatb.2008.01.006 
2 Figure 1. Desulfurization kinetics using $\mathrm{CuY} 1$ and $\mathrm{CuY} 2$ zeolites powder in olefin-free

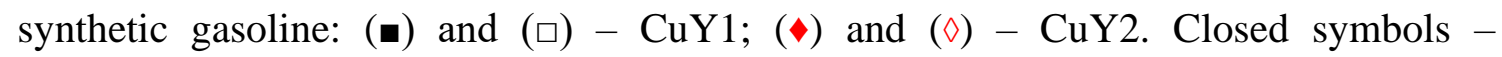

4 concentration in the liquid phase; Open symbols - concentration in the solid phase.

5 Conditions: $[\mathrm{S}]_{0} \sim 381 \mathrm{mg} / \mathrm{L}$; agitation $=900 \mathrm{rpm}, \mathrm{T}=25^{\circ} \mathrm{C}$.

6 Figure 2. Adsorption isotherms for $\mathrm{CuY} 1$ and $\mathrm{CuY} 2$ zeolites powder adsorbents in 7 olefin-free synthetic gasoline. Conditions: $\mathrm{T}=25^{\circ} \mathrm{C}$, agitation $=900 \mathrm{rpm}$.

8 Figure 3. Kinetics of $\mathrm{S}$ adsorption using $\mathrm{CuY} 1$ zeolite powder and pellets in synthetic 9 gasoline solution: $(\Delta)$ and $(\Delta)-\mathrm{CuY} 1$ powder; $(\bullet)$ and $(\circ)-\mathrm{CuY} 1$ pellets. Closed 10 symbols - concentration in the liquid phase; Open symbols - concentration in the solid phase. Conditions: $[\mathrm{S}]_{0} \sim 381 \mathrm{mg} / \mathrm{L} ; \mathrm{T}=25^{\circ} \mathrm{C}$.

Figure 4. Adsorption kinetic for CuY1 zeolites pellets in synthetic gasoline solution.

Figure 5. Adsorption isotherm for $\mathrm{CuY} 1$ zeolites pellets in synthetic gasoline solution. Conditions: $\mathrm{T}=25^{\circ} \mathrm{C}$, agitation $=900 \mathrm{rpm}$.

Figure 6. Breakthrough curves for the adsorptive removal of sulfur from model gasoline with olefin over the $\mathrm{CuY} 1$ pelletized adsorbent. Experiment $\mathrm{A} \approx 1000 \mathrm{mg} \mathrm{S} / \mathrm{L}$ and 3.6 $\mathrm{mL} / \mathrm{min}$ flow rate; Experiment $\mathrm{B} \approx 1000 \mathrm{mg} \mathrm{S} / \mathrm{L}$ and $1.8 \mathrm{~mL} / \mathrm{min}$ flow rate; Experiment $\mathrm{C} \approx 400 \mathrm{mg} \mathrm{S} / \mathrm{L}$ and $3.6 \mathrm{~mL} / \mathrm{min}$ flow rate; Experiment $\mathrm{D} \approx 400 \mathrm{mg} \mathrm{S} / \mathrm{L}$ and $1.8 \mathrm{~mL} / \mathrm{min}$ flow rate.

Figure 7. Regeneration of the CuY1 pelletized adsorbent in a packed bed column. (a) Regeneration $\mathrm{A} \approx 980 \mathrm{mg} \mathrm{S} / \mathrm{L}$ and $3.6 \mathrm{~mL} / \mathrm{min}$ flow rate; (b) Regeneration $\mathrm{B} \approx 980 \mathrm{mg}$ $\mathrm{S} / \mathrm{L}$ and $1.8 \mathrm{~mL} / \mathrm{min}$ flow rate. 
2 Table 1. Operation parameters for the breakthrough curves of the synthetic gasoline 3 desulfurization by $\mathrm{CuY} 1$ pellets

Experiment Experiment Experiment Experiment
$\mathbf{A}$
B
C
D

\begin{tabular}{lcccc}
\hline Length $(\mathrm{cm})$ & 39.0 & 39.3 & 40.0 & 40.0 \\
\hline Flow rate (mL/min) & 3.6 & 1.8 & 3.6 & 1.8 \\
\hline $\begin{array}{l}\text { Sulfur concentration } \\
(\mathrm{mg} / \mathrm{L})\end{array}$ & 1008 & 950 & 400 & 390 \\
\hline
\end{tabular}

4

5 Table 2. Methods of the adsorbed bed regeneration.

\begin{tabular}{ll}
\hline Method & Procedures \\
\hline $\mathbf{1}$ & $\begin{array}{l}\text { i) Drying in a laboratory stove at } 160{ }^{\circ} \mathrm{C} \\
\text { ii) Muffle furnace at } 350{ }^{\circ} \mathrm{C} \text { for } 3 \mathrm{~h}\end{array}$ \\
\hline $\mathbf{2}$ & $\begin{array}{l}\text { i) Rotary evaporator drying (Fisatom F-802) } \\
\text { ii) Muffle furnace at } 350{ }^{\circ} \mathrm{C} \text { for } 3 \mathrm{~h}\end{array}$ \\
\hline $\mathbf{3}$ & i) Drying at room temperature \\
& ii) Muffle furnace at $350{ }^{\circ} \mathrm{C}$ for $3 \mathrm{~h}$ \\
\hline
\end{tabular}

6

7 Table 3. Kinetic parameters of the pseudo-first and pseudo-second order models for the 8 adsorption of sulfur compounds.

\begin{tabular}{|c|c|c|c|c|c|}
\hline \multicolumn{6}{|c|}{ Pseudo-first order model } \\
\hline Adsorbent & $\begin{array}{c}k_{1} \\
(1 / \mathrm{min})\end{array}$ & $\begin{array}{c}\boldsymbol{q}_{e q} \\
(\mathbf{m g ~ S} / \mathbf{g})\end{array}$ & $\begin{array}{c}r_{a d s(i)} \\
(\mathbf{m g} / \mathrm{g} / \mathbf{m i n})\end{array}$ & $R^{2}$ & $\begin{array}{c}S_{R}^{2} \\
(\mathbf{m g} / \mathbf{g})^{2}\end{array}$ \\
\hline $\mathrm{CuY} 1$ powder & $1.24 \pm 0.08$ & $1.04 \pm 0.01$ & 1.290 & 0.997 & $5.0 \times 10^{-4}$ \\
\hline $\mathrm{CuY} 2$ powder & $0.07 \pm 0.02$ & $0.60 \pm 0.04$ & 0.042 & 0.967 & $1.9 \times 10^{-3}$ \\
\hline \multicolumn{6}{|c|}{ Pseudo-second order model } \\
\hline Adsorbent & $\begin{array}{c}k_{2} \\
(\mathrm{~g} / \mathrm{mg} / \mathrm{min})\end{array}$ & $\begin{array}{c}q_{e q} \\
(\mathrm{mg} \mathrm{S} / \mathrm{g})\end{array}$ & $\begin{array}{c}r_{a d s(i)} \\
(\mathbf{m g} / \mathbf{g} / \mathbf{m i n})\end{array}$ & $R^{2}$ & $\begin{array}{c}S_{R^{2}} \\
(\mathbf{m g} / \mathbf{g})^{2} \\
\end{array}$ \\
\hline CuY1 powder & $2.2 \pm 0.2$ & $1.08 \pm 0.01$ & 2.566 & 0.997 & $4.5 \times 10^{-4}$ \\
\hline CuY2 powder & $0.11 \pm 0.054$ & $0.73 \pm 0.05$ & 0.059 & 0.981 & $1.0 \times 10^{-3}$ \\
\hline
\end{tabular}


1 Table 4. Langmuir-Freundlich parameters for olefin-free synthetic gasoline

2 desulfurization by zeolites powder adsorbents.

\begin{tabular}{ccccc}
\hline Zeolite & $\boldsymbol{K}(\mathbf{L} / \mathbf{m g})$ & $\boldsymbol{q}_{\boldsymbol{s}}(\mathbf{m g ~ S} / \mathbf{g})$ & $\boldsymbol{m}$ & $\mathbf{R}^{2}$ \\
\hline CuY1 & $8.77 \times 10^{-9}$ & 3.74 & 3.20 & 0.987 \\
\hline CuY2 & $3.38 \times 10^{-11}$ & 2.50 & 4.64 & 0.981 \\
\hline
\end{tabular}

3

4 Table 5. Kinetic parameters of the pseudo-first and pseudo-second order models for the 5 adsorption of sulfur compounds.

\begin{tabular}{|c|c|c|c|c|c|}
\hline \multicolumn{6}{|c|}{ Pseudo-first order model } \\
\hline Adsorbent & $\begin{array}{c}k_{1} \\
(1 / \mathrm{min}) \\
\end{array}$ & $\begin{array}{c}q_{e q} \\
(\mathrm{mg} \mathrm{S} / \mathrm{g})\end{array}$ & $\begin{array}{c}r_{a d s(i)} \\
(\mathbf{m g} / \mathbf{g} / \mathbf{m i n})\end{array}$ & $R^{2}$ & $\begin{array}{c}S_{R}{ }^{2} \\
(\mathrm{mg} / \mathrm{g})^{2}\end{array}$ \\
\hline CuY1 powder & $0.23 \pm 0.05$ & $2.20 \pm 0.07$ & 0.506 & 0.898 & $4.8 \times 10^{-2}$ \\
\hline $\mathrm{CuY} 1$ pellets & $0.13 \pm 0.02$ & $2.19 \pm 0.06$ & 0.285 & 0.935 & $3.4 \times 10^{-2}$ \\
\hline \multicolumn{6}{|c|}{ Pseudo-second order model } \\
\hline Adsorbent & $\begin{array}{c}k_{2} \\
(\mathrm{~g} / \mathrm{mg} / \mathrm{min})\end{array}$ & $\begin{array}{c}q_{e q} \\
(\mathrm{mg} \mathrm{S} / \mathrm{g})\end{array}$ & $\begin{array}{c}r_{a d s(i)} \\
(\mathrm{mg} / \mathrm{g} / \mathrm{min})\end{array}$ & $R^{2}$ & $\begin{array}{c}S_{R}{ }^{2} \\
(\mathrm{mg} / \mathrm{g})^{2}\end{array}$ \\
\hline CuY1 powder & $0.21 \pm 0.04$ & $2.26 \pm 0.05$ & 1.072 & 0.965 & $1.6 \times 10^{-2}$ \\
\hline $\mathrm{CuY} 1$ pellets & $0.10 \pm 0.01$ & $2.30 \pm 0.04$ & 0.529 & 0.979 & $1.1 \times 10^{-2}$ \\
\hline
\end{tabular}

6

7 Table 6. Langmuir-Freundlich parameters for synthetic gasoline desulfurization by CuY1

8 zeolites pellets.

\begin{tabular}{ccccc}
\hline Zeolite & $\boldsymbol{K}(\mathrm{L} / \mathbf{m g})$ & $\boldsymbol{q}_{s}(\mathbf{m g ~ S} / \mathbf{g})$ & $\boldsymbol{m}$ & $\mathbf{R}^{2}$ \\
\hline CuY1 - pellets & $2.00 \times 10^{-5}$ & 4.33 & 2.00 & 0.996
\end{tabular}

9

10 
1 Table 7. Sulfur uptake capacities onto different adsorbents in a fixed-bed column

2 system.

\begin{tabular}{|c|c|c|c|}
\hline $\begin{array}{l}\text { Adsorbent } \\
\text { type }\end{array}$ & Sulfur compounds & $\begin{array}{l}\text { Adsorption } \\
\text { capacity } \\
(\mathbf{m g ~ S} / g)\end{array}$ & Reference \\
\hline $\mathrm{CuY} 1$ pellets & $\begin{array}{l}\text { Model gasoline with olefin ( } 50 \% \text { of n-octane, } 10 \% \text { of } \\
\text { cyclohexane } 20 \% \text { of toluene, } 20 \% \text { of cyclohexene, } \\
\text { and ( } 1000 \mathrm{ppm} \mathrm{S}) \text { of thiophene. }\end{array}$ & $2.97^{\mathrm{a}}$ & This work \\
\hline $\begin{array}{l}\text { Pdy/MCM } \\
\text { (palladium } \\
\text { containing } \\
\text { mesoporous } \\
\text { silica) }\end{array}$ & $\begin{array}{l}\text { Commercial ultra low sulfur diesel, doped with } 300 \\
\text { ppmw of 4-methyldibenzothiophene. }\end{array}$ & $2.67^{\mathrm{a}}$ & $\begin{array}{l}\text { (Teymouri et } \\
\text { al. 2013) }\end{array}$ \\
\hline $\begin{array}{l}\mathrm{NaY} \\
\mathrm{AgY} \\
\mathrm{CeY}\end{array}$ & $n$-heptane and thiophene (model fuel). & $\begin{array}{l}0.39^{\mathrm{b}} \\
11.01^{\mathrm{b}} \\
13.67^{\mathrm{b}}\end{array}$ & $\begin{array}{l}\text { (Lin et al. } \\
\text { 2011) }\end{array}$ \\
\hline $\mathrm{Ni} / \mathrm{Al}_{2} \mathrm{O}_{3}$ & $\begin{array}{l}\text { Commercial diesel contained benzothiophene (BT), } \\
\text { dibenzothiophene } \quad(\mathrm{DBT}) \text {, } \\
\text { dibenzothiophene }(4-\mathrm{MDBT}) \text { and } 4,6 \text {-methyl } \\
\text { dibenzothiophene (4,6 MDBT) as major refractory } \\
\text { cyclic compounds (S: } 325 \mathrm{ppmw}) .\end{array}$ & $0.50^{\mathrm{b}}$ & $\begin{array}{l}\text { (Sarda et al. } \\
\text { 2012) }\end{array}$ \\
\hline $\begin{array}{l}\mathrm{Cu}(\mathrm{I}) \text {-beta } \\
\mathrm{Ag}(\mathrm{I}) \text {-beta }\end{array}$ & $\begin{array}{l}\text { Model gasoline containing about } 200 \mathrm{ppm} \text { of total } \\
\text { sulfur compounds (thiophene } 150 \mathrm{ppm} \text { and } \\
\text { benzothiophene } 50 \mathrm{ppm} \text { ) in cyclohexane. }\end{array}$ & $\begin{array}{l}7.66^{\mathrm{a}} \\
7.60^{\mathrm{a}}\end{array}$ & $\begin{array}{l}\text { (Gong et al. } \\
\text { 2009) }\end{array}$ \\
\hline $\begin{array}{c}\mathrm{CuY} \\
\mathrm{PdCl} 2 / \gamma- \\
\mathrm{Al} 2 \mathrm{O} 3 \\
\mathrm{Ag} / \mathrm{TiO} 2\end{array}$ & JP5 fuel (1172 ppmw sulfur) & $\begin{array}{l}1.50^{\mathrm{b}} \\
9.67^{\mathrm{b}} \\
8.20^{\mathrm{b}}\end{array}$ & $\begin{array}{l}\text { (Nair and } \\
\text { Tatarchuk } \\
\text { 2011) }\end{array}$ \\
\hline $\mathrm{Ni}-\mathrm{Y}$ & $\begin{array}{l}\text { Heavy straight-run gasoline contained aromatics, } \\
\text { naphthenes, olefins, paraffins and about } 140 \mathrm{ppmw} \\
\text { the total sulfur concentration. }\end{array}$ & $2.31^{\mathrm{b}}$ & $\begin{array}{l}\text { (Dastanian } \\
\text { and } \\
\text { Seyedeyn- } \\
\text { Azad 2010) }\end{array}$ \\
\hline $\begin{array}{l}\text { CuNaY-M75- } \\
\text { I }\end{array}$ & $\begin{array}{l}\text { Model fuel containing thiophene, } n \text {-heptane and } \\
\text { benzene. }\end{array}$ & $8.8^{a}$ & $\begin{array}{l}\text { (Li et al. } \\
\text { 2009) }\end{array}$ \\
\hline
\end{tabular}

3

adsorption dynamic capacity; ${ }^{b}$ adsorption equilibrium capacity. 
Table 8. Transport Parameters obtained from pore diffusion model.

\begin{tabular}{ccccc}
\hline Transport Parameters & Experiment A & Experiment B & Experiment C & Experiment D \\
\hline Molecular diffusivity, $D_{A m}\left(\mathrm{~cm}^{2} / \mathrm{min}\right)$ & 0.0016 & 0.0016 & 0.0016 & 0,0016 \\
\hline Internal mass transfer coefficient, $k_{i}(\mathrm{~cm} / \mathrm{min})$ & 0.1001 & 0.1001 & 0.1001 & 0.9861 \\
\hline External mass transfer coefficient, $k_{e}(\mathrm{~cm} / \mathrm{min})$ & 0.9859 & 0.9696 & 0.0432 & 0.9600 \\
\hline Global mass transfer coefficient $K_{L}(\mathrm{~cm} / \mathrm{min})$ & 0.0432 & 0.0432 & 0.0432 \\
\hline Sphericity, $\varphi$ & 0.83 & 0.83 & 2.6429 \\
\hline Coefficient of axial dispersion, $D_{l}\left(\mathrm{~cm}^{2} / \mathrm{min}\right)$ & 2.6419 & 1.3472 & 1.3482 \\
\hline
\end{tabular}

2 
$1 \quad$ Figures

2

$3 \quad$ Figure 1

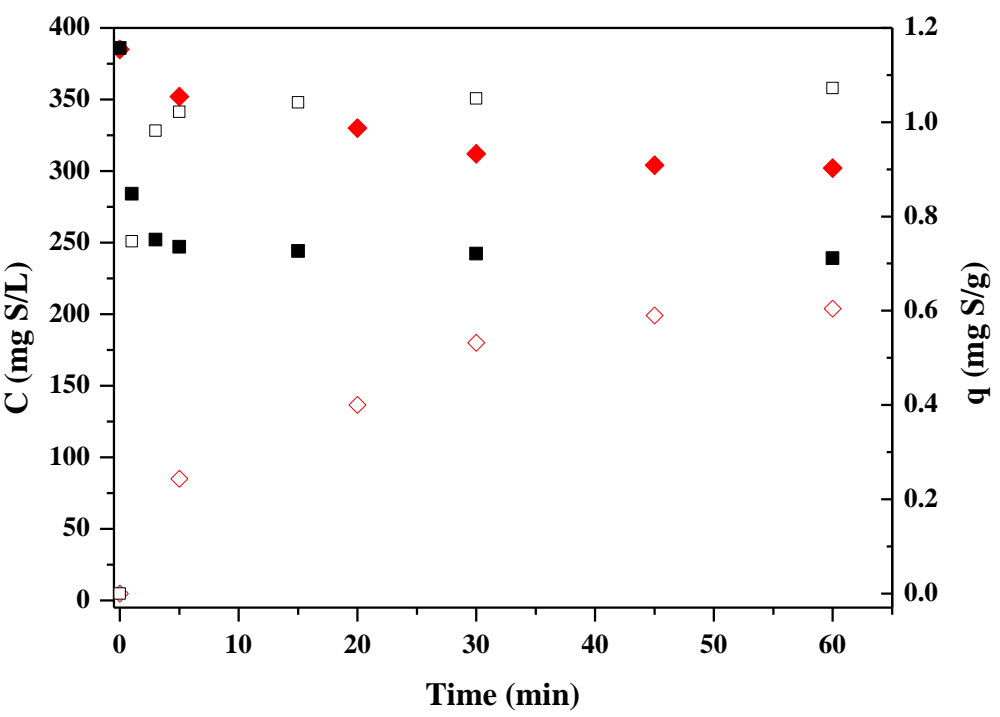

5

6 Figure 2

7

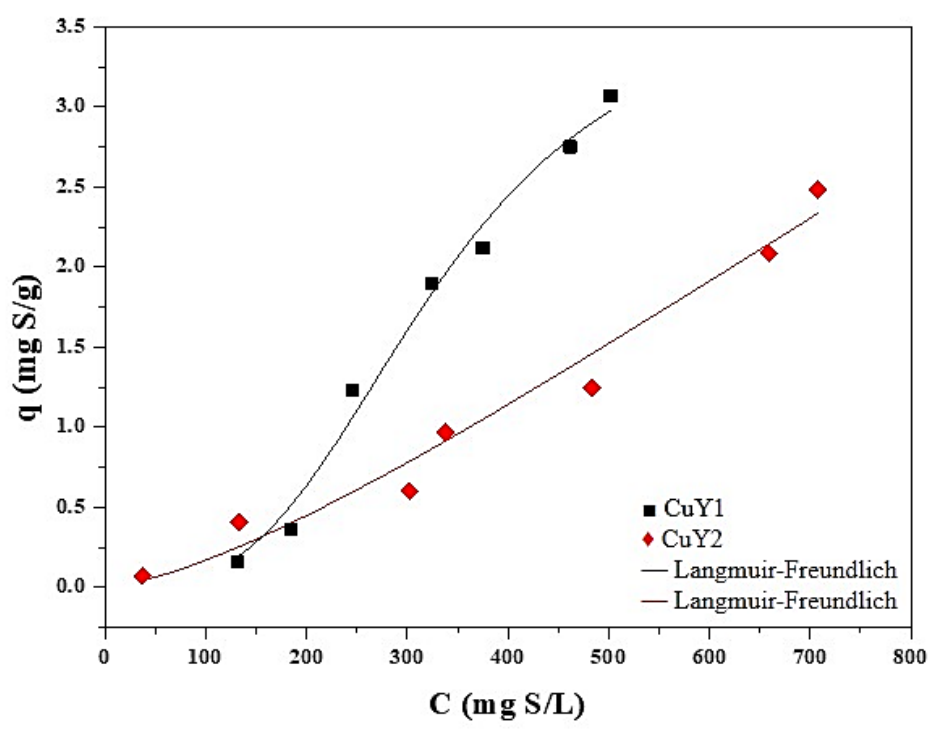

8

9

10

11

12 
$1 \quad$ Figure 3

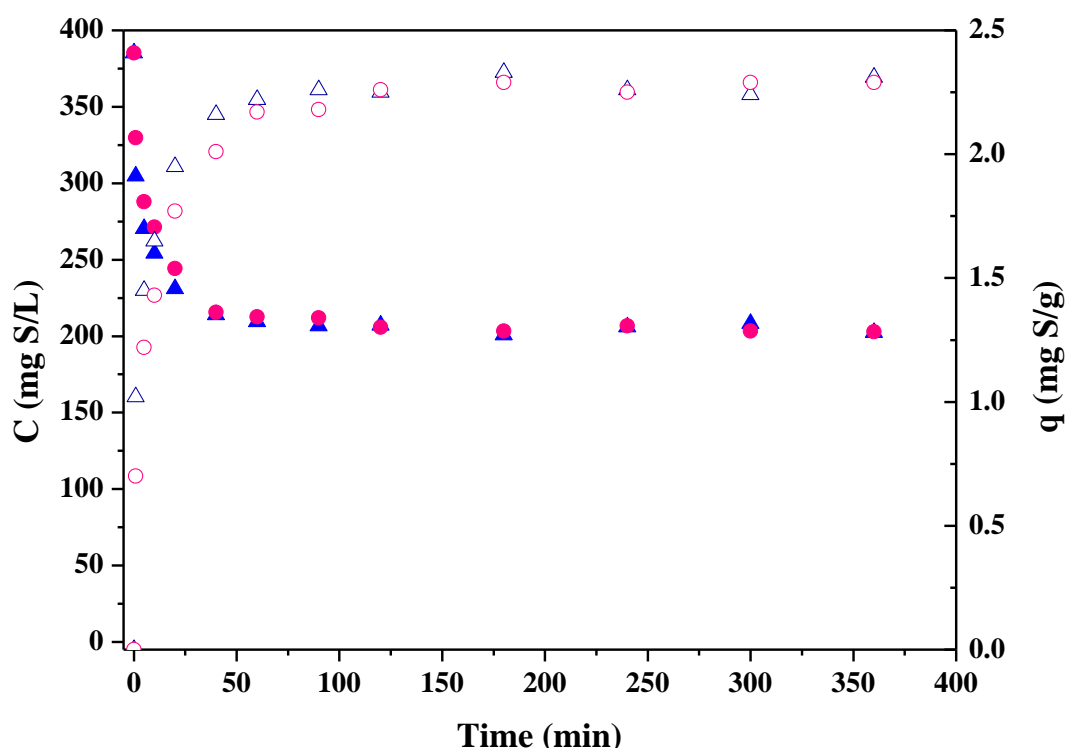

2

3

$4 \quad$ Figure 4

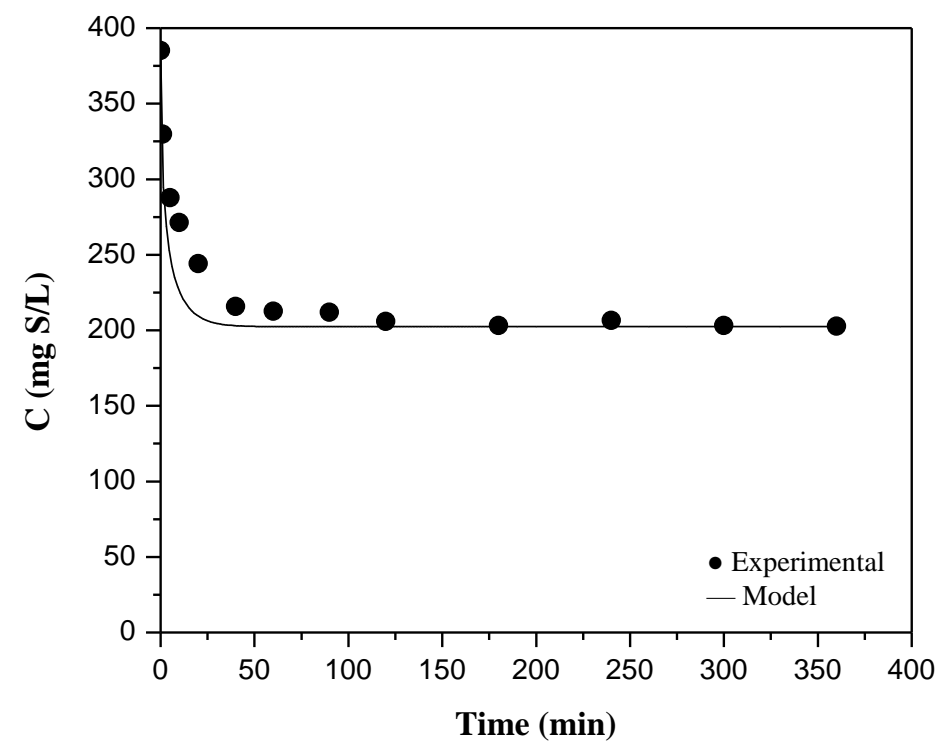

5 
Figure 5

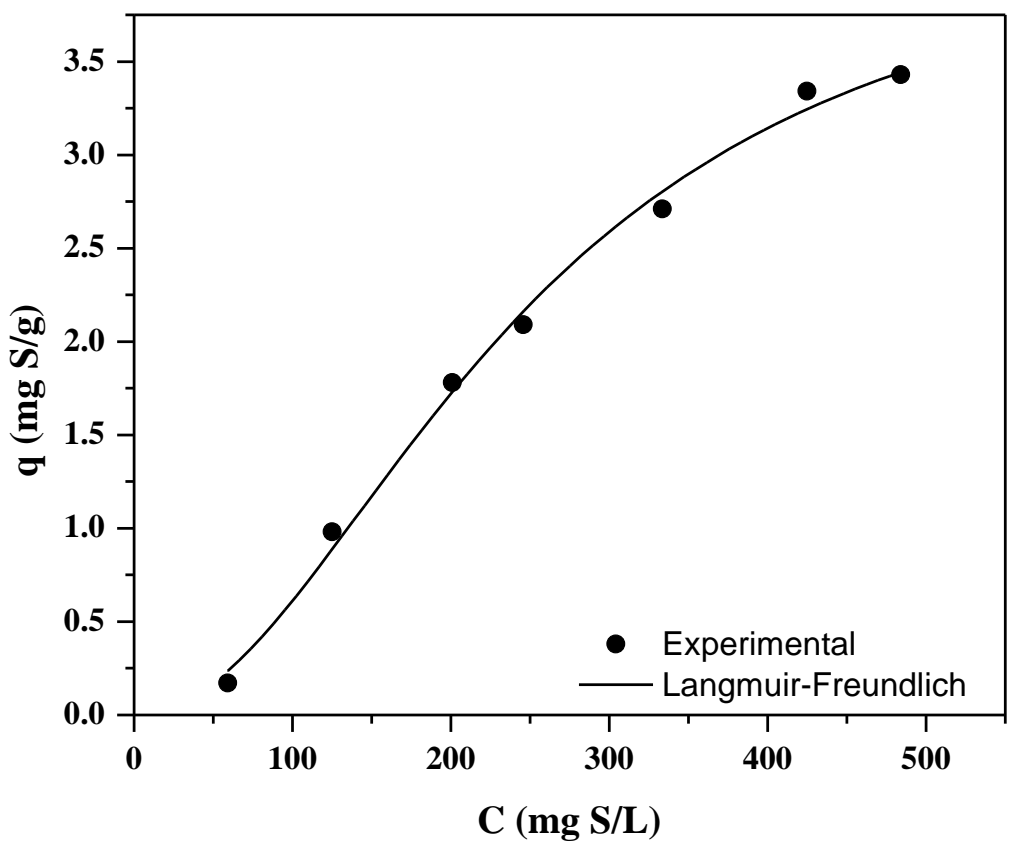

3

$4 \quad$ Figure 6

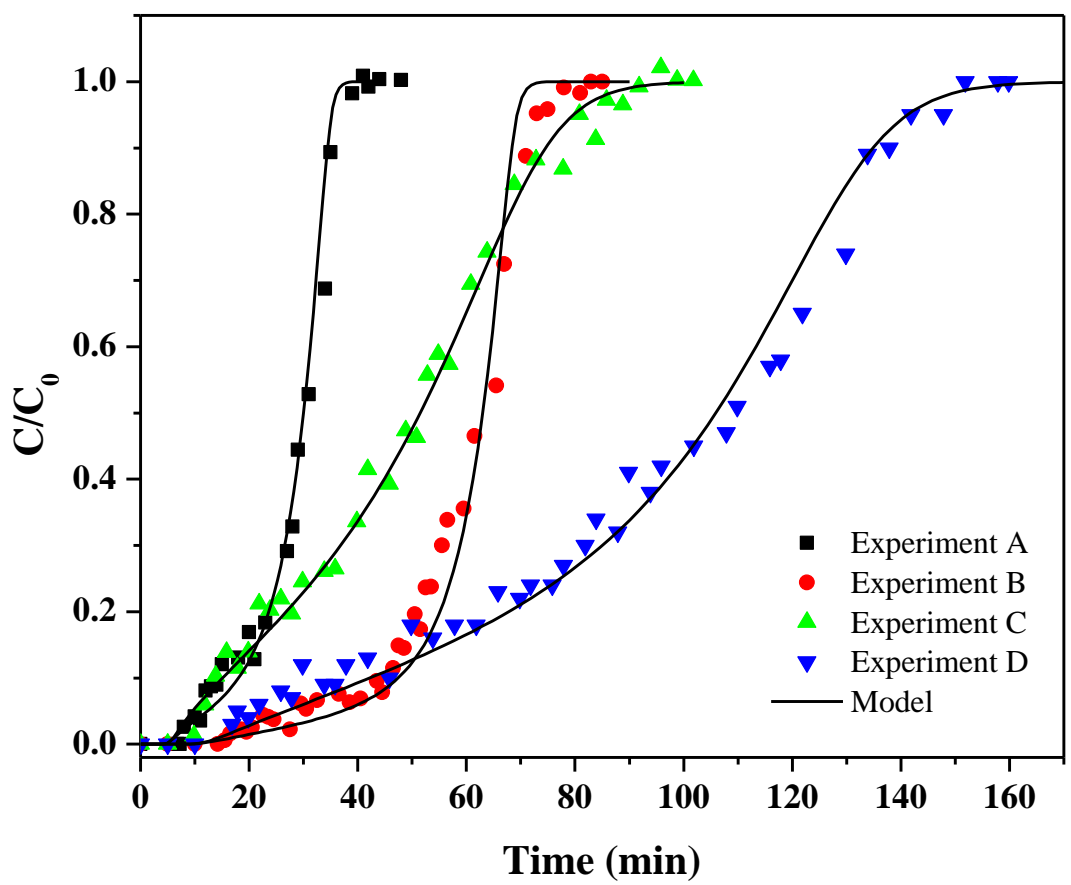




\section{$1 \quad$ Figure 7}

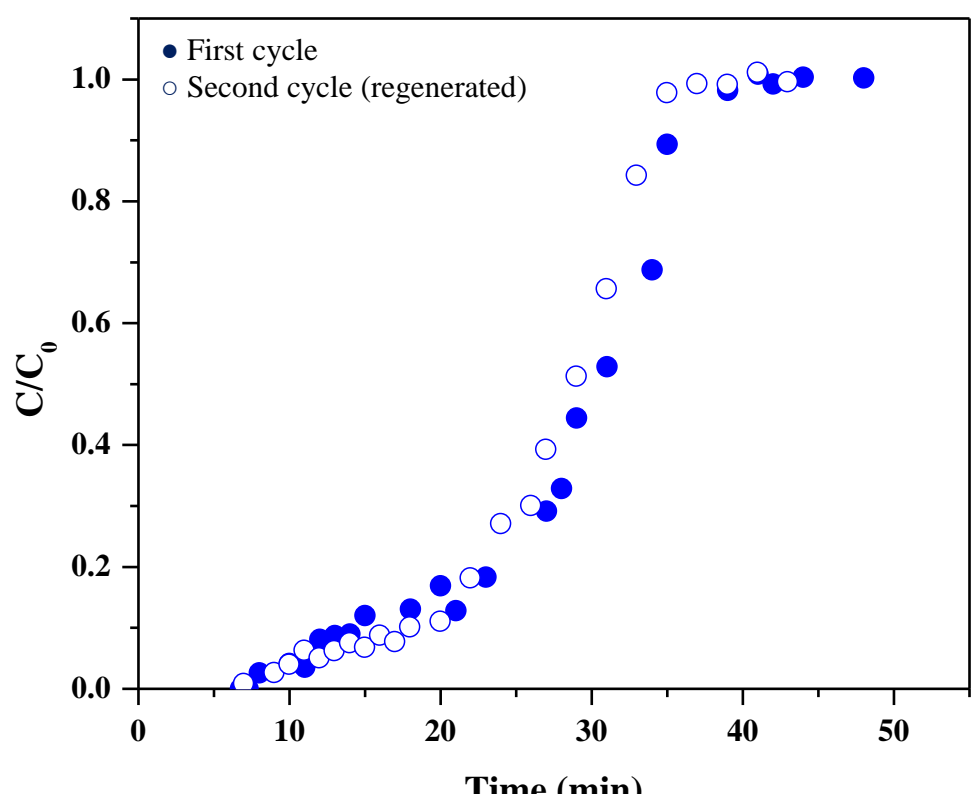

(a)

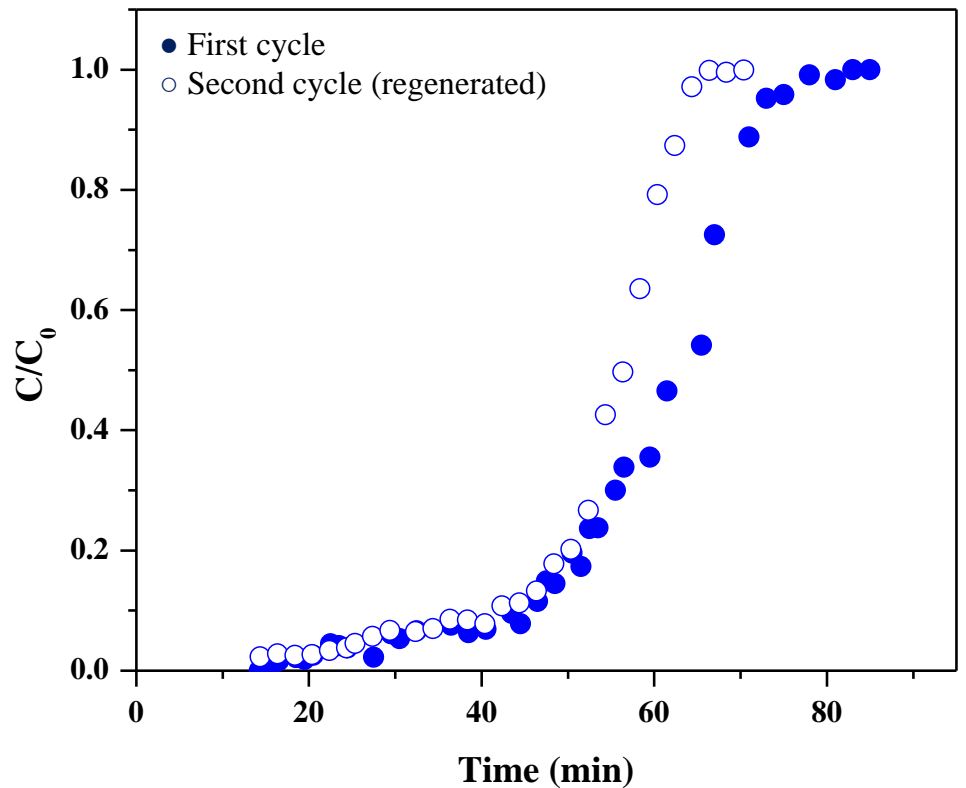

(b)

2 